\title{
Prevalence and burden of multiple sclerosis-related fatigue: a systematic literature review
}

\author{
Abril Oliva Ramirez ${ }^{1}$, Alexander Keenann ${ }^{2 *}$, Olivia Kalau ${ }^{1}$, Evelyn Worthington ${ }^{1}$, Lucas Cohen ${ }^{1}$ and Sumeet Singh ${ }^{1}$
}

\begin{abstract}
Background: Multiple sclerosis (MS) is a chronic, demyelinating disease of the central nervous system that results in progressive and irreversible disability. Fatigue is one of the most common MS-related symptoms and is characterized by a persistent lack of energy that impairs daily functioning. The burden of MS-related fatigue is complex and multidimensional, and to our knowledge, no systematic literature review has been conducted on this subject. The purpose of this study was to conduct a systematic literature review on the epidemiology and burden of fatigue in people with multiple sclerosis (pwMS).

Methods: Systematic searches were conducted in MEDLINE, Embase, and Evidence-Based Medicine Reviews to identify relevant studies of fatigue in pwMS. English-language records published from 2010 to January 2020 that met predefined eligibility criteria were included. We initially selected studies that reported quality of life (QoL) and economic outcomes according to categories of fatigue (e.g., fatigued vs non-fatigued). Studies assessing associations between economic outcomes and fatigue as a continuous measure were later included to supplement the available data.

Results: The search identified 8147 unique records, 54 of which met the inclusion criteria. Of these, 39 reported epidemiological outcomes, 11 reported QoL, and 9 reported economic outcomes. The supplementary screen for economic studies with fatigue as a continuous measure included an additional 20 records.

Fatigue prevalence in pwMS ranged from 36.5 to $78.0 \%$. MS-related fatigue was consistently associated with significantly lower QoL. Results on the economic impact of fatigue were heterogeneous, but most studies reported a significant association between presence or severity of fatigue and employment status, capacity to work, and sick leave. There was a gap in evidence regarding the direct costs of MS-related fatigue and the burden experienced by caregivers of pwMS.
\end{abstract}

Conclusion: Fatigue is a prevalent symptom in pWMS and is associated with considerable QoL and economic burden. There are gaps in the evidence related to the direct costs of MS-related fatigue and the burden of fatigue on caregivers. Addressing fatigue over the clinical course of the disease may improve health and economic outcomes for patients with MS.

Keywords: Multiple sclerosis, Fatigue, Burden of illness, Systematic review, Prevalence, Economic, Quality of life

\footnotetext{
* Correspondence: AKeenan1@its.jnj.com

${ }^{2}$ Health Economics and Market Access, Janssen Research \& Development,

LLC, Titusville, NJ, USA

Full list of author information is available at the end of the article
}

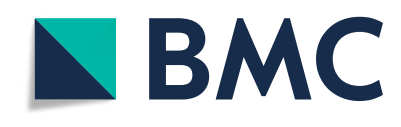

두 The Author(s). 2021 Open Access This article is licensed under a Creative Commons Attribution 4.0 International License, which permits use, sharing, adaptation, distribution and reproduction in any medium or format, as long as you give appropriate credit to the original author(s) and the source, provide a link to the Creative Commons licence, and indicate if changes were made. The images or other third party material in this article are included in the article's Creative Commons licence, unless indicated otherwise in a credit line to the material. If material is not included in the article's Creative Commons licence and your intended use is not permitted by statutory regulation or exceeds the permitted use, you will need to obtain permission directly from the copyright holder. To view a copy of this licence, visit http://creativecommons.org/licenses/by/4.0/. The Creative Commons Public Domain Dedication waiver (http://creativecommons.org/publicdomain/zero/1.0/) applies to the data made available in this article, unless otherwise stated in a credit line to the data. 


\section{Introduction}

Multiple sclerosis (MS) is a chronic inflammatory disease that results in progressive demyelination in the central nervous system. Approximately 2.3 million people worldwide have been diagnosed with MS, with the highest prevalence in North America, Western Europe, and Australasia [1, 2]. The onset of MS usually occurs in early adulthood [2, 3], however, 3-5\% of people with MS (pwMS) are diagnosed before this age $[2,4]$. The clinical course of MS can be differentiated by disease history, progression of irreversible disability, and the presence or absence of acute disease relapses. Four courses of MS have been identified: clinically isolated syndrome (CIS), relapsingremitting MS (RRMS), secondary progressive MS (SPMS), and primary progressive MS (PPMS). Approximately $85 \%$ of pwMS are initially diagnosed with RRMS, which may eventually progress to SPMS with or without superimposed relapses [5].

Fatigue, which can be defined as a "significant lack of physical and/or mental energy that is perceived by the individual or caretaker to interfere with usual or desired activity," [6] is one of the most common and debilitating symptoms of MS. [2, 7-10] Several studies have been published describing the prevalence and impact of fatigue on QoL and employment [11-13]; however, to our knowledge, no systematic literature review (SLR) synthesizing the available evidence has been published. Therefore, the primary objective of the current report was to conduct an SLR synthesizing the published data on the prevalence, economic cost, and QoL burden of fatigue in pwMS.

\section{Methods}

An SLR was conducted to identify primary studies reporting epidemiological, economic, or QoL-related outcomes of MS-related fatigue in patients with CIS, RRMS, and/or SPMS, based on a predefined search strategy. The SLR adhered to the methodological and reporting guidelines outlined in the Preferred Reporting Items for Systematic Reviews and Meta-Analysis (PRISMA) checklist [14].

\section{Search strategy}

The search strategy was developed and performed by an experienced medical information specialist through an iterative process in consultation with the review team. Peer review was completed by a second information specialist using the Peer Review of Electronic Search Strategies (PRESS) Checklist [15]. Databases searched included Ovid MEDLINE ${ }^{\oplus}$, including Epub Ahead of Print and In-Process \& Other Non-Indexed Citations, Embase, and the following Evidence-Based Medicine Reviews (EBMR) databases: Health Technology Assessment, and the National Health Service (NHS) Economic Evaluation Database. All searches were performed on January 27, 2020.

The search incorporated controlled vocabulary (e.g., "Multiple Sclerosis", "Incidence", "Prevalence", "Fatigue") and keywords (e.g., "RRMS", "occurrence", "epidemiology", "tired", "cost"). Results were limited to the publication years 2000 to present and excluded conference abstracts published prior to 2018 .

A comprehensive search of the grey literature was conducted using the Grey Matters checklist [16]. The following conference websites were also searched for relevant abstracts published within the past 2 years: American Academy of Neurology (AAN), American Neurology Association (ANA), Academy of Managed Care Pharmacy (AMCP), Americas Committee for Treatment and Research in Multiple Sclerosis (ACTRIMS), European Academy of Neurology (EAN), European Committee for Treatment and Research in Multiple Sclerosis (ECTRIMS), International Society for Pharmacoeconomics and Outcomes (ISPOR) America and Europe.

The reference lists of included articles were also reviewed, and records identified as potentially relevant were screened.

For additional details, please see Additional file 1.

\section{Study eligibility criteria}

The predefined inclusion and exclusion criteria pertaining to the population, intervention, comparator, outcome, and study design (PICOS) are presented in Table 1. Studies were included that evaluated at least $70 \%$ patients with RRMS, SPMS, or CIS, and that reported at least one outcome related to the epidemiological burden, humanistic burden, and/or economic burden of MS-related fatigue. Eligibility criteria were initially designed to select for studies reporting fatigue as a categorical measure (i.e., fatigued vs. nonfatigued patients, or low vs. high levels of fatigue) and its relationship with relevant outcomes. However, the eligibility criteria were revised to include studies reporting economic outcomes that evaluated fatigue as a continuous measure due to the sparse data available from the categorical studies in this area.

\section{Study selection}

Study screening was performed using the systematic review software DistillerSR (Evidence Partners, Ontario, Canada). Screening was conducted by two reviewers who independently reviewed the citation titles and abstracts identified in the literature search to assess study eligibility based on the predefined PICOS criteria. Potentially relevant records were then screened by two reviewers in full-text form. Reasons for exclusion were documented at the full-text stage 
Table 1 PICOS criteria for inclusion and exclusion of studies

\begin{tabular}{|c|c|}
\hline Inclusion Criteria & Exclusion Criteria \\
\hline \multicolumn{2}{|l|}{ Population } \\
\hline - People with MS and fatigue & $\begin{array}{l}\text { - Studies in which greater than } 30 \% \text { of subjects have MS types } \\
\text { other than RRMS, SPMS, or CIS (e.g. PPMS, RIS) } \\
\text { - Studies reporting fatigue as a continuous measure a }\end{array}$ \\
\hline \multicolumn{2}{|l|}{ Intervention } \\
\hline - Any or none & $\cdot$ N/A \\
\hline \multicolumn{2}{|l|}{ Comparator } \\
\hline - Any or none & $\cdot$ N/A \\
\hline \multicolumn{2}{|l|}{ Outcomes } \\
\hline $\begin{array}{l}\text { - Epidemiologic measures of MS-related fatigue (i.e., prevalence or incidence, } \\
\text { current or projected) } \\
\text { - Health resource utilization and costs (e.g., hospitalization, physician visits, } \\
\text { drugs, assistive devices, long-term care) associated with MS-related fatigue } \\
\text { - Lost productivity/income experienced by patients, caregivers, family } \\
\text { members, society associated with MS-related fatigue } \\
\text { - Community costs (e.g., personal support professionals, home care) associated } \\
\text { with MS-related fatique }\end{array}$ & $\begin{array}{l}\text { - Studies that do not report methodology for assessing or } \\
\text { identifying fatigue } \\
\text { - Studies that do not report an outcome of interest in relation to } \\
\text { MS-related fatigue, e.g., } \\
{ }^{\circ} \text { Only overall health costs for MS reported } \\
{ }^{\circ} \text { Only isolated dimensions of HRQoL or patient function (e.g. } \\
\text { gait, cognitive impairment, anxiety/depression) reported }\end{array}$ \\
\hline
\end{tabular}

with MS-related fatigue

- Other costs (e.g., disability payments or other income support) associated

with MS-related fatigue

- Measures of patient-reported health-related quality of life (HRQOL) using a

validated general health measure or disease-specific instrument

\section{Study Design}

- Primary studies (e.g., surveys, epidemiological studies, natural history and disease progression studies, observational studies, registries or other realworld studies, $\mathrm{BOI}$ studies, clinical trials, economic evaluations) reporting one or more of the above outcomes

\section{Language}

- Articles in English ${ }^{b}$

- Opinions, editorials, narrative reviews

\section{Publication types and time frame}

- 2010-present

- All publication types (peer-reviewed articles, grey literature such as reports

from government or other organizations, conference abstracts)

- Conference abstracts from the past 2 years only

anitially, only studies reporting fatigue as a categorical measure (i.e., fatigued vs. non-fatigued patients, or levels of fatigue) were included. However, the eligibility criteria were later revised to include studies that evaluated fatigue as a continuous measure for outcomes related to economic burden, due to the sparse data identified in this area from categorical studies

${ }^{\mathrm{b}}$ Search was not restricted to English language studies, but non-English studies were excluded in study selection phase

Abbreviations: BOI burden of illness, CIS clinically isolated syndrome, FACIT Functional Assessment of Chronic Illness Therapy, FSS Fatigue Severity Scale, HRQoL health-related quality of life, MFIS Modified Fatigue Impact Scale, MS multiple sclerosis, N/A not applicable, PPMS primary progressive multiple sclerosis, RCT randomized controlled trial, RIS radiologically isolated syndrome, RRMS relapsing-remitting multiple sclerosis, SLR systematic literature review, SPMS secondary progressive multiple sclerosis, VAS visual analogue scale

and are provided in Additional file 2. Any disagreements during study screening were resolved by discussion or by a third independent reviewer.

\section{Data extraction}

Details for selected articles were collected using a standardized data extraction template in Microsoft Excel. Data extraction was performed by a single reviewer and validated by a second reviewer. General study information (reference identification, first author last name, publication year, and country/region of study) was extracted, in addition to a predefined list of epidemiological, economic, and QoL outcomes.

\section{Data synthesis}

When multiple publications reporting data from the same study were identified, the most comprehensive data were used. When multiple analyses were conducted in a single study, the analysis with the most robust design was selected to be included in the synthesis, based on the following hierarchy: multivariate regression analyses; univariate regression analyses; correlation analyses; and statistical tests of association (e.g., t-test, $x^{2}$ test).

\section{Results}

\section{Identification and description of studies}

A total of 9960 records were identified through the database and grey literature searches. After de-duplication, 
8147 records remained for title and abstract review. At the title and abstract stage, 244 full-text records were selected to be reviewed. Of these, 54 were found to fulfill the inclusion criteria. Results for each stage of the screening process are presented in Fig. 1. Of the included records, 40 (35 unique studies) examined epidemiological parameters (prevalence or incidence), nine investigated effects of fatigue on economic outcomes (costs, employment, etc.), and 11 investigated the effects of fatigue on QoL. Among these, one study reported data related to all three outcomes [11], two reported both epidemiology and QoL data $[17,18]$ and one reported both epidemiology and economic data [19]. An additional 20 records were identified through the supplementary screen for economic studies with fatigue as a continuous measure.

\section{Epidemiology}

\section{Prevalence}

The SLR search identified 39 publications reporting the prevalence of fatigue in pwMS, based on 35 unique datasets (Additional file 3). Twenty-five studies used self-reported measurements administered in different settings (online, at the clinic, etc.) [11, 18, 2042]. Physicians and/or researchers administered the assessment in four studies [17, 19, 43, 44] and seven studies did not specify an administration method [4551]. Most studies ( $n=25$ studies) were conducted in Europe, North America, and Australasia [18, 21-24, 26-33, 36-39, 42, 43, 45, 48-52] and an additional five records were linked to the same international study in which most of the participants reported living in North America, Australasia, and Europe [11, $25,34,35,40]$. The remaining five datasets were from South America, the Middle East, or the region was not reported [17, 19, 20, 46, 47]. Sample sizes ranged from 26 to 5475 participants.

\section{Adult population}

Twenty-seven studies reported results for adults with MS. Across these studies, the prevalence of fatigue ranged from 18.2 to $97.0 \%$ (Table 2). The wide range of values reported was likely due to the considerable

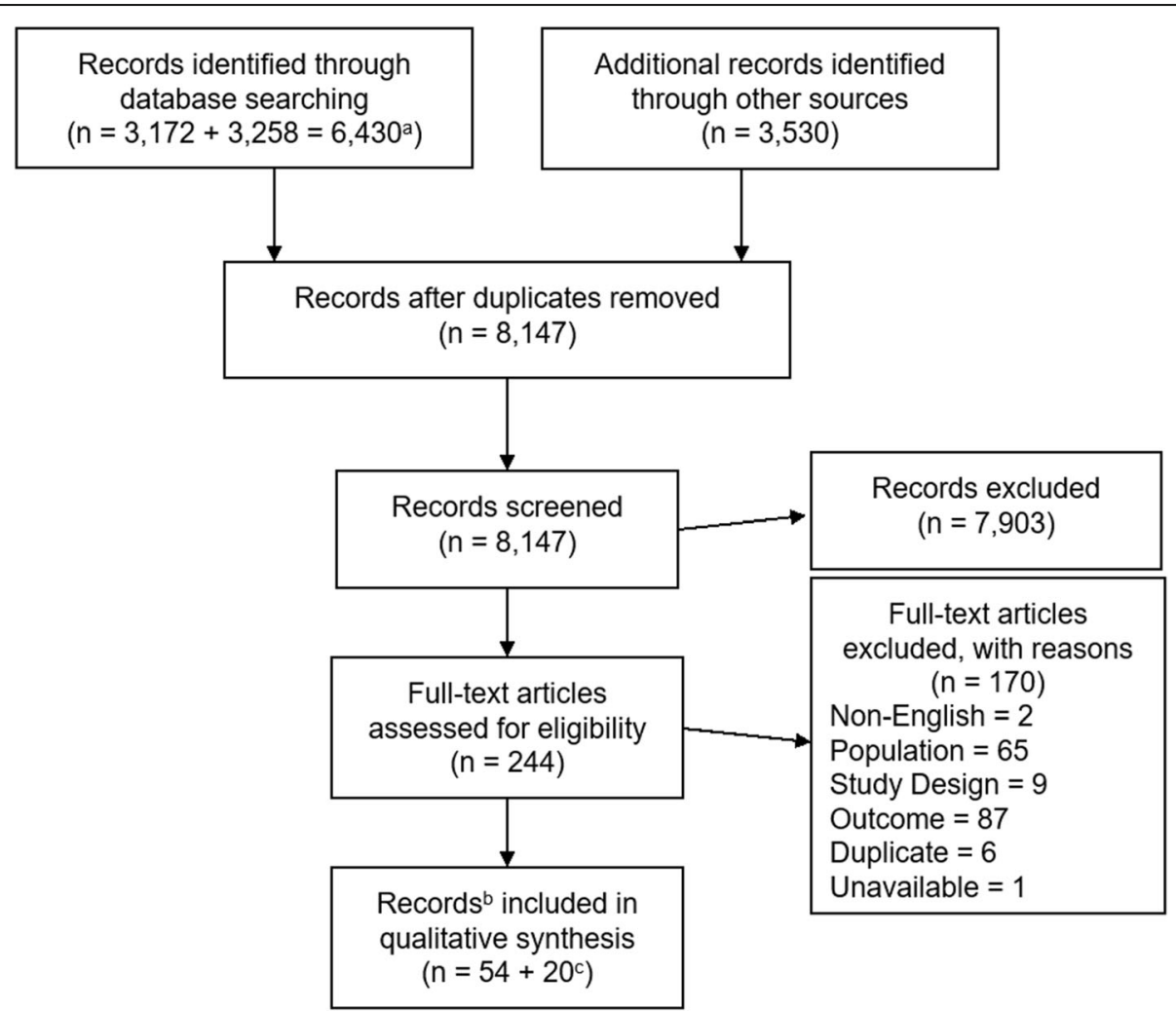

Fig. 1 Search and exclusion process. ${ }^{a}$ Searches were run separately for (1) epidemiology $(n=3172)$ and (2) economic/QoL studies ( $\left.n=3258\right)$. Each search was then deduplicated (epidemiology $=3081$; economic/QoL $=3229$ ). The two searches were then combined and deduplicated once again $(n=4631) .{ }^{\mathbf{b}}$ In some cases, more than one record was identified for a given study/population. ${ }^{c}$ Supplemental search of economic studies with fatigue measured as a continuous parameter. Abbreviations: MA = meta-analysis; NMA = network meta-analysis; QoL $=$ quality of life; $S L R=$ systematic literature review 
Table 2 Results - Epidemiology

\begin{tabular}{|c|c|c|c|c|}
\hline Author (year) & Tool to Measure Fatigue; Cut-off Value Used & Outcome(s) & $\begin{array}{l}n \text { evaluated } \\
\text { for fatigue }\end{array}$ & Fatigue (\%) \\
\hline \multicolumn{5}{|l|}{ Adult } \\
\hline Alvarenga-Filho (2015) & MFIS; $\geq 38$ & Prevalence & NR & 35.0 \\
\hline Anens (2014) & $\mathrm{FSS} ; \geq 4$ & Prevalence & 285 & 61.7 \\
\hline Battaglia (2017) & VAS (0-10); NR & Prevalence & 997 & 96.0 \\
\hline Calabrese (2017) & VAS (0-10); NR & Prevalence & 703 & 93.0 \\
\hline Fiest (2016) & D-FIS; $\geq 5.0$ & Prevalence, Incidence & 943 & 78.0 \\
\hline Flachenecker (2017) & VAS (0-10); NR & Prevalence & 5233 & 96.0 \\
\hline Fricska-Nagy (2016) & $\mathrm{FIS} ; \mathrm{NR}$ & Prevalence & 402 & 62.4 \\
\hline Hadgkiss (2013) & $\mathrm{FSS} ; \geq 4$ & Prevalence & 2143 & 65.7 \\
\hline Havrdova (2017) & VAS (0-10); NR & Prevalence & 727 & 92.0 \\
\hline Kratz (2016) & 11-point scale; Occurrence: $>0$, Severe: $>6$ & Prevalence & 180 & 88.0 \\
\hline Labuz-Roszak (2012) & FSS; $>36^{\mathrm{a}}$ & Prevalence & 122 & 61.5 \\
\hline Larnaout (2018) ${ }^{\mathrm{b}}$ & $\mathrm{FSS} ;>4, \mathrm{MFIS} ;>38^{\mathrm{c}}$ & Prevalence & NR & 60.0 \\
\hline Lebrun-Frenay (2017) & VAS (0-10); NR & Prevalence & 454 & 95.0 \\
\hline Oreja-Guevara (2017) & VAS (0-10); NR & Prevalence & 446 & 92.0 \\
\hline Pentek (2017) & VAS (0-10); NR & Prevalence & 508 & 94.0 \\
\hline Pokryszko-Dragan (2016) & $\mathrm{FSS} ; \geq 4$ & Prevalence & 44 & 18.2 \\
\hline Reilly (2017) & $\mathrm{FSS} ; \geq 4$ & Prevalence & 2079 & 65.6 \\
\hline Rooney (2019) & $\mathrm{FSS} ; \geq 5$ & Prevalence & 412 & 68.7 \\
\hline Runia (2015) & FSS; $\geq 5$ & Prevalence & 127 & 46.5 \\
\hline Selmaj (2017) & VAS (0-10); NR & Prevalence & 408 & 97.0 \\
\hline Thompson (2017) & VAS (0-10); NR & Prevalence & 769 & 96.0 \\
\hline Uitdehaag (2017) & VAS (0-10); NR & Prevalence & 381 & 96.0 \\
\hline van der Vuurst de Vries (2017) & $\mathrm{FSS} ; \geq 5$ & Prevalence & NR & 35.3 \\
\hline von Bismarck (2018) & FSMC; At least mild fatigue (> 42 Pt.) & Prevalence & 1069 & 36.5 \\
\hline Weiland (2015) & FSS; $\geq 4$ & Prevalence & 2138 & 65.6 \\
\hline Weiland (2019) ${ }^{d}$ & $\mathrm{FSS}_{;} \geq 4$ & Prevalence, Longitudinal & $\begin{array}{l}1268 \\
1268 \\
509\end{array}$ & $\begin{array}{l}56.0 \\
62.5 \\
53.8\end{array}$ \\
\hline Wood (2013) & $\mathrm{FSS} ; \geq 5$ & Prevalence & 192 & 53.7 \\
\hline \multicolumn{5}{|l|}{ Pediatric } \\
\hline Florea (2019) & FSS; Moderate $\geq 3$ & Prevalence & 23 & 43.0 \\
\hline Goretti (2010) & $\mathrm{FSS} ; \geq 4$ & Prevalence & 56 & 20.0 \\
\hline Parrish (2013) & PedsQL Multidimensional Fatigue Scale; Total Fatigue $\geq 36$ & Prevalence & 24 & 29.2 \\
\hline van's Gravesande (2019) ${ }^{\text {b }}$ & $\begin{array}{l}\text { PedsQL Multidimensional Fatigue Scale; Mildly impaired: } \\
\text { score 1-2 SDs below healthy controls, severely impaired: } \\
\text { score > } 2 \text { SDs below healthy controls }\end{array}$ & Prevalence & 106 & 40.6 \\
\hline \multicolumn{5}{|l|}{ Mixed or unknown age } \\
\hline Garcia (2019) a, b, e & $\begin{array}{l}\text { FSS; Persistent fatigue } \geq 28 \text {, NFI-MS/BR; persistent } \\
\text { fatigue } \geq 30\end{array}$ & Prevalence, Longitudinal; Mixed age & $\begin{array}{l}38 \\
26\end{array}$ & $\begin{array}{l}\text { FSS: } \mathbf{7 4 . 4}, 54.0 \\
\text { NFI-MS/BR: } \mathbf{6 4 . 0}, 47.0\end{array}$ \\
\hline Kaya Aygunoglu (2015) & FSS; $\geq 4$ & Prevalence & 120 & 70.0 \\
\hline Razazian (2014) & $\mathrm{FSS} ; \geq 5$ & Prevalence & 300 & 62.3 \\
\hline Rupprecht (2018) ${ }^{\text {b }}$ & MFIS; NR & Prevalence & NR & 45.0 \\
\hline
\end{tabular}

${ }^{a}$ Refers to the total FSS score, not the average as is mostly calculated

${ }^{\mathrm{b}}$ Conference abstract

'Unclear if FSS or MFIS was used to report fatigue percentage

${ }^{\mathrm{d}}$ Baseline data are presented in bold text and validation cohort in italics

${ }^{\text {}}$ Baseline data are presented in bold text

Abbreviations: D-FIS daily FIS, FIS Fatigue Impact Scale, FSS Fatigue Severity Scale, MFIS modified FIS, FSMC Fatigue Scale for Motor and Cognitive Functions, NFIS$M S / B R$ Neurological Fatigue Index - multiple sclerosis, Brazilian Portuguese version, NR not reported, VAS visual analogue scale 
heterogeneity across studies in the instruments or criteria used to classify patients as having fatigue.

\section{Prevalence of Fatigue Reported by Different Scales:} Eleven studies did not use fatigue-specific validated instruments in estimating prevalence; ten studies used a 10-point visual analogue scale (VAS, cut-off not reported) and one study used an 11-point scale (fatigue presence defined as a score over 0 ) to measure fatigue. The prevalence of fatigue in these 11 studies ranged from 88.0 to $97.0 \%$ (Table 2). Validated fatigue scales (Table 3) were used in 16 studies (17 datasets) to define fatigue: seven studies used the Fatigue Severity Scale $(\mathrm{FSS}) \geq 4$, four used FSS $\geq 5$, one used FSS $>36$, two used the Modified Fatigue Impact Scale (MFIS) $\geq 38$, one used the daily Fatigue Impact Scale (D-FIS) $\geq 5$, one used the Fatigue Scale for Motor and Cognitive Functions $($ FSMC) $>42$, and one used the Fatigue Impact Scale (FIS) with no cut-off reported. In these studies, the prevalence of fatigue ranged from 18.2 to $78.0 \%$.

Prevalence of Fatigue in Relevant Subgroups: Three studies exclusively included patients with CIS, in which fatigue was observed in 18.2 to $46.5 \%$ of participants $[33,36,49]$. Excluding the CIS-only studies, the prevalence of fatigue ranged from 35.0 to $97.0 \%$ based on both validated and non-validated instruments.

One study specifically examined fatigue in patients with no disability by restricting inclusion to those with Expanded Disability Status Scale [EDSS] scores between 0 and 1.5. Patients with EDSS scores in this range exhibit no or minimal neurological signs of MS. The prevalence of fatigue was estimated to be $35.0 \%$ in this sample [20].

The 12 studies that measured fatigue using a validated scale, did not restrict enrolment to CIS only, and did not restrict by level of disability may provide the most reliable and generalizable estimates of fatigue prevalence in the overall MS population. The prevalence of fatigue in these studies ranged from 36.5 to $78.0 \%$ [11, 18, 21, 25, $28,34,35,40,42,47,50,51]$. Eight of these studies (describing nine datasets) recruited 300 or more participants, the number required to estimate fatigue prevalence in pwMS with a standard error of $\leq 5 \%$, assuming that fatigue prevalence was $60 \%$; these studies reported prevalence estimates ranging from 36.5 to $78.0 \%[11,25,34,35,40,42,48,50]$.

Longitudinal Data: A single large international study (1401 participants) estimated the prevalence of fatigue at

Table $\mathbf{3}$ Characteristics of validated fatigue scales

\begin{tabular}{|c|c|c|c|}
\hline Validated fatigue scales & Domains/Components & $\begin{array}{l}\text { Range of possible } \\
\text { scores }\end{array}$ & $\begin{array}{l}\text { Cut-offs for defining clinically } \\
\text { relevant fatigue }\end{array}$ \\
\hline Fatigue Severity Scale (FSS) & $\begin{array}{l}9 \text { items: activities of daily living, life participation, } \\
\text { and sleep }\end{array}$ & $\begin{array}{l}\text { Total: 9-63 } \\
\text { Mean of all scores: } \\
1-7\end{array}$ & $\begin{array}{l}\text { Total: > } 36 \text { [53] } \\
\text { Mean of all scores: } \geq 4 \text { [53] or } \\
\geq 5 \text { [54] }\end{array}$ \\
\hline Fatigue Impact Scale (FIS) & 40 items: physical, cognitive, and social & $\begin{array}{l}\text { Total: } 0-160 \\
\text { Physical: 0-40 } \\
\text { Cognitive: 0-40 } \\
\text { Social: } 0-80\end{array}$ & Cut-off not reported [9] \\
\hline Modified Fatigue Impact Scale (MFIS) & $\begin{array}{l}21 \text { items (full-length) or } 5 \text { items (abbreviated): } \\
\text { physical, cognitive, and psychosocial functioning }\end{array}$ & $\begin{array}{l}\text { 21-item version: 0- } \\
84 \text { (total) } \\
\text { Physical: 0-36 } \\
\text { Cognitive: 0-40 } \\
\text { Psychosocial: 0-8 } \\
\text { 5-item version: 0-20 }\end{array}$ & $\begin{array}{l}\text { 21-item (total): } \geq 38[55] \text { or } \\
\geq 45[56] \text { a }\end{array}$ \\
\hline Daily Fatigue Impact Scale (D-FIS) & 8 items: physical, cognitive, and psychosocial & Total: 0-32 & Cut-off not reported [57] \\
\hline $\begin{array}{l}\text { Fatigue Scale for Motor and Cognitive } \\
\text { Functions (FSMC) }\end{array}$ & 20 items: Cognition and gait & $\begin{array}{l}\text { Total: } 20-100 \\
\text { Cognitive: 10-50 } \\
\text { Physical: } 10-50\end{array}$ & $\begin{array}{l}\text { Total [58] } \\
\text { Mild fatigue: > 42 } \\
\text { Moderate fatigue: > } 52 \\
\text { Severe fatigue: > } 62 \\
\text { Cognitive } \\
\text { Mild fatigue: > } 21 \\
\text { Moderate fatigue: > } 27 \\
\text { Severe fatigue: }>33 \\
\text { Physical } \\
\text { Mild fatigue: }>21 \\
\text { Moderate fatigue: > } 26 \\
\text { Severe fatigue: }>31\end{array}$ \\
\hline
\end{tabular}


baseline (56.0\%) and after 2.5 years (62.5\%) using the FSS with fatigue defined as an FSS score $\geq 4$ [40].

\section{Pediatric and mixed-aged population}

Four studies examined fatigue in a pediatric population, reporting a prevalence of 20.0 to $43.0 \%$ (Table 2).

Two additional studies included a mix of adult and pediatric patients $[17,19]$ and another two did not report age-related eligibility criteria [46, 48]. In these four studies, the prevalence of MS-related fatigue ranged from 45.5 to $74.4 \%$.

One study recorded fatigue using the FSS as well as the Neurological Fatigue Index - multiple sclerosis, Brazilian Portuguese version (NFIS-MS/BR) at three time points with three-month intervals; fatigue was defined as FSS $\geq 28$ or NFI-MS/BR $\geq 30$. Of the 26 patients who attended the three interviews, $54.0 \%$ of the patients reported persistent fatigue at all three timepoints when measured with the FSS, and $47 \%$ with the NFIS-MS/BR [46].

\section{Incidence}

One Canadian study reported an incidence of fatigue per 100 of 28.9 (95\% Confidence Interval [CI]: 23.4, 35.1) at year one after study enrolment, 29.9 (95\% CI: 24.5, 35.9) at year two, and overall cumulative incidence of 38.8 (95\% CI: 32.7, 45.3) [59].

\section{Economic burden}

A total of nine studies reported the economic burden associated with fatigue in pwMS, in which fatigue was reported categorically (Additional file 3) [11, 13, 19, 6065]. Most studies were cross-sectional in design $(n=7)$. Sample sizes ranged from 90 to 5173. Most studies were conducted in Europe, North America, and Australasia $(n=6)$. Over half of the studies used the FSS to measure fatigue $(n=5)$ and the most commonly reported outcomes were related to employment $(n=7)$. All studies were of economic outcomes related to the impact of fatigue on the patient themselves; no records were identified pertaining to the societal or caregiver burden of MS-related fatigue. Two studies examined the relationship between fatigue and direct costs, such as drug costs and physician visits $[60,64]$. Seven studies in adult populations reported indirect costs such as employmentrelated outcomes in relation to fatigue. Results for each study are available in Table 4.

\section{Direct costs}

Two studies reported the association between fatigue and direct costs. A longitudinal study conducted in Canada examined the association between baseline fatigue (D-FIS $\geq 5$ ) and physician visit and hospitalization rates in pwMS. After adjusting for age, sex, comorbidity count, and other baseline characteristics, no significant associations were found between fatigue and physician visits (adjusted rate ratio $=1.06$ [95\% CI: 0.97, 1.17]) or hospitalizations (adjusted rate ratio $=1.82$ [95\% CI: 0.86, 3.87]) [64].

A cross-sectional cost analysis conducted in Brazil reported that higher non-disease-modifying therapy (DMT) direct costs were not associated $(p=0.83)$ with impact of fatigue (MFIS, Brazilian Portuguese version [MFIS-BR], cut-off not reported) after adjusting for disability, gender, educational level, MS relapse, selfreported comorbidities, MS type, and occupation [60].

\section{Unemployment}

Two European (Poland and Italy) and one North American (USA and Canada) cross-sectional studies assessed whether fatigue was predictive of unemployment in pwMS $[62,63,65]$. Both European studies reported that the odds of being unemployed were higher in pwMS experiencing fatigue (FSS > 4) than in non-fatigued patients after adjustment for patient characteristics such as sex, age, and disability status, although the relationship was only statistically significant in the Polish study $(\mathrm{OR}=2.63,95 \% \mathrm{CI}: 1.02,6.90$ in the Polish study [62]; $\mathrm{OR}=2.10, p=0.179$ in the Italian study [63]). The North American study also reported that fatigued participants (Fatigue Performance Scale [FPS] 3-5) had statistically significantly higher odds of not working $(\mathrm{OR}=1.93$; 95\% CI: 1.64, 2.26) after adjustment for clinical course, age, and other patient characteristics [65].

One large international cross-sectional study reported that being unemployed was predictive of fatigue (FSS $\geq$ 4; $\mathrm{OR}=2.15 ; 95 \%$ CI: $1.48,3.11$ ) [11]. Similarly, a Norwegian longitudinal study found fatigue (FSS $\geq 4$ ) was predictive of unemployment at baseline (OR $=3.03[95 \%$ CI: 1.19, 7.71]) [61]. Finally, an Iranian study found that employment status varied between fatigued and nonfatigued participants $(p=0.025)$ [19].

\section{Other employment-related outcomes}

A North American cross-sectional study found that fatigued participants (FPS 3-5) had statistically significantly higher odds of working less than $35 \mathrm{~h}$ per week $(\mathrm{OR}=1.63$; 95\% CI: 1.04, 2.33), cutting back hours in the past 6 months $(\mathrm{OR}=7.19$; 95\% CI: 3.29, 15.70), missing work days in the past 6 months $(\mathrm{OR}=4.73 ; 95 \% \mathrm{CI}$ : $2.67,8.37)$, and receiving disability benefits $(\mathrm{OR}=1.99$; $95 \%$ CI: $1.39,2.84)$, after adjustment for clinical course, age, age at diagnosis, sex, comorbidities, cognition, hand function, and disability [65].

A Dutch study found that high fatigue (NFI-MS 2130) predicted high work absence when compared to low fatigue (NFI-MS 0-10; OR = 15.80; 95\% CI: 3.00, 83.26) and intermediate fatigue (NFI-MS 11-20; OR =11.22; 
Table 4 Results - Economic burden (fatigue assessed as categorical)

\begin{tabular}{|c|c|c|c|c|c|c|c|c|}
\hline $\begin{array}{l}\text { Author } \\
\text { (year) }\end{array}$ & Type of Analysis & $\begin{array}{l}\text { Sample } \\
\text { Size (n) }\end{array}$ & $\begin{array}{l}\text { Cut-off for } \\
\text { Fatigue }\end{array}$ & Outcome & Predictor(s) & Value & $95 \% \mathrm{Cl}$ & $p$-value \\
\hline da Silva (2016) & Multivariate ANOVA & 210 & $\begin{array}{l}\text { MFIS Low impact } \\
(39-58), \text { High impact } \\
(\geq 59)\end{array}$ & Non-DMT costs & $\begin{array}{l}\text { EDSS, gender, educational level, } \\
\text { MFIS-BR (cut-off NR), MS relapse, } \\
\text { any self-reported comorbidities, } \\
\text { MS type, and occupation }\end{array}$ & NR & NR & 0.83 \\
\hline \multirow[t]{3}{*}{ Doesburg (2019) } & \multirow[t]{3}{*}{$\begin{array}{l}\text { Multiple logistic } \\
\text { regression }\end{array}$} & \multirow[t]{3}{*}{78} & \multirow{3}{*}{$\begin{array}{l}\text { NFI-MS Low } \\
(0-10 \mathrm{pts}), \text { Middle } \\
(11-20), \text { High } \\
(21-30)\end{array}$} & \multirow[t]{3}{*}{ High work absence } & $\begin{array}{l}\text { Marital status, relapses in the past } \\
\text { year, NFI-MS (middle vs low) }\end{array}$ & $\mathrm{OR}=1.41$ & $0.42,4.76$ & 0.581 \\
\hline & & & & & $\begin{array}{l}\text { Marital status, relapses in the past } \\
\text { year, NFI-MS (high vs low) }\end{array}$ & $\mathrm{OR}=15.80$ & $3.00,83.26$ & 0.001 \\
\hline & & & & & $\begin{array}{l}\text { Marital status, relapses in the past } \\
\text { year, NFI-MS (high vs middle) }\end{array}$ & $\mathrm{OR}=11.22$ & $2.13,59.16$ & NR \\
\hline \multirow[t]{2}{*}{ Grytten (2017) } & $\begin{array}{l}\text { Univariate logistic } \\
\text { regression }\end{array}$ & 91 & \multirow[t]{2}{*}{$F S S \geq 4$} & $\begin{array}{l}\text { Unemployment at } \\
\text { baseline }\end{array}$ & \multirow[t]{2}{*}{$\mathrm{FSS} \geq 4$} & $\mathrm{OR}=3.03$ & $1.19,7.71$ & 0.02 \\
\hline & $\begin{array}{l}\text { Univariate Cox } \\
\text { regression }\end{array}$ & 40 & & $\begin{array}{l}\text { Time to awarding } \\
\text { disability pension }\end{array}$ & & $H R=2.03$ & $0.86,4.78$ & 0.09 \\
\hline Koziarska (2018) & $\begin{array}{l}\text { Multivariate logistic } \\
\text { regression }\end{array}$ & 150 & $\mathrm{FSS}>4$ & Unemployment & FSS > 4, EDSS > 3, PQD5, KNS & $\mathrm{OR}=2.63$ & $1.02,6.90$ & 0.046 \\
\hline Lorefice (2018) & $\begin{array}{l}\text { Multivariate logistic } \\
\text { regression }\end{array}$ & 123 & $\mathrm{FSS}>4$ & Unemployment status & $\begin{array}{l}\text { Female, age, education, age at } \\
\text { onset of MS, disease duration, EDSS, } \\
\text { AES-S }>35, \text { BDI-II }>14 \text {, FSS }>\mathbf{4}\end{array}$ & $\mathrm{OR}=2.10$ & NR & 0.179 \\
\hline \multirow[t]{2}{*}{ McKay (2018) } & \multirow{2}{*}{$\begin{array}{l}\text { Generalized } \\
\text { estimating } \\
\text { equations }\end{array}$} & \multirow[t]{2}{*}{340} & \multirow[t]{2}{*}{ D-FIS $\geq 5$} & Hospitalizations & $\begin{array}{l}\text { Age, sex, EDSS, D-FIS } \geq \mathbf{5} \\
\text { comorbidity count, HUI pain }\end{array}$ & $\operatorname{adj} R R=1.82$ & $0.86,3.87$ & NR \\
\hline & & & & Physician visit & $\begin{array}{l}\text { Age, sex, D-FIS } \geq \mathbf{5} \text {, smoker, } \\
\text { comorbidity count, HUI pain, } \\
\text { HUI cognition }\end{array}$ & $\operatorname{adj} R R=1.06$ & $0.97,1.17$ & NR \\
\hline \multirow[t]{2}{*}{ Razazian (2014) } & \multirow[t]{2}{*}{ Pearson's $\times 2$ test } & \multirow[t]{2}{*}{300} & \multirow[t]{2}{*}{$F S S \geq 5$} & Medication use & $\mathrm{FSS} \geq 5$ vs $\mathrm{FSS}<5$ & NR & NR & 0.002 \\
\hline & & & & Employment status & $\mathrm{FSS} \geq 5$ vs FSS $<5$ & NR & NR & 0.025 \\
\hline \multirow[t]{5}{*}{ Salter (2017) } & \multirow{5}{*}{$\begin{array}{l}\text { Multivariable } \\
\text { logistic } \\
\text { regression }\end{array}$} & 4607 & \multirow{5}{*}{$\begin{array}{l}\text { FPS Normal }(0) \text {, } \\
\text { Mild }(1,2) \text {, } \\
\text { Moderate-to-severe } \\
(3-5)\end{array}$} & Not working & \multirow{5}{*}{$\begin{array}{l}\text { MS clinical course, age, age at } \\
\text { diagnosis, sex, number of } \\
\text { comorbidity categories, CPS, } \\
\text { FPS severe (vs. normal), } \\
\text { HPS, PDDS }\end{array}$} & $\mathrm{OR}=1.93$ & $1.64,2.26$ & $<0.0001$ \\
\hline & & 1921 & & Working < $35 \mathrm{~h} /$ week & & $\mathrm{OR}=1.63$ & $1.04,2.33$ & 0.0031 \\
\hline & & 1788 & & $\begin{array}{l}\text { Cut back hrs. } \\
\text { Past } 6 \text { mos. }\end{array}$ & & $\mathrm{OR}=7.19$ & $3.29,15.70$ & $<0.0001$ \\
\hline & & 1706 & & $\begin{array}{l}\text { Missed work days } \\
\text { past } 6 \text { mos. }\end{array}$ & & $\mathrm{OR}=4.73$ & $2.67,8.37$ & $<0.0001$ \\
\hline & & 1717 & & $\begin{array}{l}\text { Receiving disability } \\
\text { benefits }\end{array}$ & & $\mathrm{OR}=1.99$ & $1.39,2.84$ & 0.0005 \\
\hline \multirow[t]{6}{*}{ Weiland (2015) } & \multirow{6}{*}{$\begin{array}{l}\text { Binary logistic } \\
\text { regression }\end{array}$} & \multirow[t]{6}{*}{2133} & \multirow[t]{6}{*}{$F S S \geq 4$} & \multirow[t]{6}{*}{$F S S \geq 4$} & Work part time & $\mathrm{OR}=1.58$ & $1.24,2.02$ & $\leq 0.001$ \\
\hline & & & & & Stay at home parent/carer & $\mathrm{OR}=19.4$ & $1.36,2.77$ & $\leq 0.001$ \\
\hline & & & & & Unemployed & $\mathrm{OR}=2.15$ & $1.48,3.11$ & $\leq 0.001$ \\
\hline & & & & & Retired due to disability & $\mathrm{OR}=5.54$ & $4.11,7.47$ & $\leq 0.001$ \\
\hline & & & & & Retired due to age & $\mathrm{OR}=1.59$ & $0.94,2.67$ & NR \\
\hline & & & & & Other (inc. student) & $\mathrm{OR}=0.834$ & $0.55,1.27$ & NR \\
\hline
\end{tabular}

Abbreviations: adjRR adjusted rate ratio, AES-S Apathy Evaluation Scale, ANOVA analysis of variance, BDI-II Beck Depression Inventory-Second Edition, CI confidence interval, CPS Cognition Performance Scale, D-FIS daily FIS, EDSS Expanded Disability Status Scale, FIS Fatigue Impact Scale, FPS Fatigue Performance Scale, FSS Fatigue Severity Scale, HPS Hand function Performance Scale, HR hazard ratio, hrs. hours, HUI Health Utility Index, KNS Hope for Success Questionnaire, MFIS modified FIS, MFIS$B R$ MFIS Brazilian Portuguese version, mos. months, NFIS-MS/BR Neurological Fatigue Index - Multiple Sclerosis, Brazilian Portuguese version, NR not reported, OR odds ratio, PDDS Patient Determined Disease Steps, PQD5 Perceived Deficits Questionnaire 5-items version, VAS visual analogue scale

95\% CI: 2.13, 59.16) after adjustment for marital status and relapses in the past year [13].

In contrast to the preceding studies, a Norwegian longitudinal study found fatigue (FSS $\geq 4$ ) did not predict time to awarding disability pension $(\mathrm{HR}=2.03$; $95 \% \mathrm{CI}$ : $0.86,4.78)[61]$.

\section{Supplemental studies}

Due to the paucity of studies regarding key economic outcomes such as direct costs and caregiver burden, supplemental screening for studies assessing fatigue as a continuous measure was conducted; 20 additional studies were identified (see Additional file 4). Also included in these 20 are studies in which it was not clear whether fatigue was analyzed as a dichotomous or continuous variable. Most studies reported cross-sectional data $(n=$ 17) [66-81]. Most studies were conducted in Europe and North America $(n=16)$ [66-68, 71-79, 81-84], one was conducted in Argentina [69], one in Australia [85], and two did not clearly report the study location [70, 
80]. FSS and MFIS were the most commonly used tools to measure fatigue, used in seven studies each. Similar to the categorical studies, the supplemental screening returned a high proportion of studies examining employment-related outcomes $(n=18)$.

Two studies reported data on direct costs of fatigue. A cross-sectional study conducted in Germany found that drug costs and total costs, including indirect costs, drugs, hospital, rehabilitation, etc., were predicted by fatigue (MFIS) after adjusting for depression, disability status, and age [77]. In contrast, a Swedish study found no significant correlation between change in fatigue (FSMC) and change in sickness benefits after 1 year of natalizumab treatment [84].

Eighteen studies reported outcomes pertaining to general indirect costs such as employment/unemployment status and work capacity. One study found that indirect costs, unlike total and drug costs, were not predicted by fatigue [77]. Six studies found an association between fatigue and employment status [67, 69, 74, 80, 82, 86]; conversely, five studies failed to find a statistically significant association [66, 68, 76, 79, 83].

Regarding work capacity outcomes, higher fatigue was associated with sick leave [70] and productivity loss [72, 85] while work capacity was correlated with [73, 81] or impacted by [71, 73, 80, 87] fatigue among other symptoms.

\section{Humanistic burden}

Eleven studies reporting QoL/humanistic burden outcomes were identified through the systematic search (Additional file 3) [11, 12, 17, 18, 88-94]. Most studies were cross-sectional in design $(n=10)[11,12,17$, 18, 89-94], and the sample sizes in all studies ranged from 31 to 2138. Geographically, studies were conducted in Europe $(n=6)$ [12, 17, 18, 88, 91, 92], Brazil $(n=3)$ [89, 93, 94] and Australia $(n=1)$ [90], with an additional international study where most of the participants reported living in North America, Australasia, and Europe [11]. QoL was assessed in six studies using MS-specific QoL assessment scales (Multiple Sclerosis Quality of Life-54 [MSQOL-54], Multiple Sclerosis International Quality of Life Questionnaire [MusiQoL], and the Functional Assessment of Multiple Sclerosis [FAMS]) [11, 12, 17, 18, 92, 94], while the 36-Item Short Form Survey (SF-36) was applied in four studies [88-91]. One study investigated the humanistic burden of MS-related fatigue by estimating utilities across fatigue levels [93]. Results for each study are available in Table 5 .

\section{Quality of life}

Ten studies investigated the relationship between fatigue and QoL in pwMS [11, 12, 17, 18, 88-92, 94]. Four were
European, two South American, two Middle Eastern, one Australian, and one international. The most commonly used scale to report fatigue was the FSS $(n=6)$, followed by the MFIS $(n=3)$, FIS $(n=1)$ and FSMC $(n=$ $1)$. The SF-36 $(n=4)$ and the MSQOL-54 $(n=4)$ instruments were most often used to measure QoL.

\section{The 36-item short form health survey}

Four studies used the SF-36 to assess QoL in pwMS. All four studies found a significant association between fatigue and at least one of the subdomains of the SF-36 [88-91].

Two studies (one European and one Brazilian) examined the relationship between fatigue and the SF-36. After adjusting for demographic and socioeconomic variables, duration of RRMS, disease severity, DMT, sleep problems, depression, anxiety and the physical or mental component summary (PCS and MCS respectively) of the SF-36, the European study found higher odds of being fatigued $(\mathrm{FSS}>4)$ with lower PCS scores $(<50)(\mathrm{OR}=$ 3.82 [95\% CI: 1.22, 5.54]), but not with lower MCS scores $(<50)(p>0.05)$ [91]. The Brazilian study found that fatigue (FSS) was associated with a reduction in the physical functioning $(p=0.006)$ and vitality components $(p=0.001)$ of the SF-36 [89].

A second European study explored how fatigue (FSS $\geq$ 5) relates to physical and mental QoL [88]. This study demonstrated that fatigue was a significant predictor of poorer than average physical $\mathrm{QoL}(\mathrm{PCS}<40) \quad(\mathrm{OR}=$ 11.00 [95\% CI: 2.94, 40.78]) and mental QoL $(\mathrm{MCS}<40)$ $(\mathrm{OR}=8.64$ [95\% CI: 2.39, 31.28]) [88].

An Australian study used the MFIS to measure cognitive (low $\leq 20$, high $>20$ ) and physical fatigue (low $\leq 23$, high $>23$ ) [90]. The study found that physical fatigue was significantly associated with the PCS $(t=$ 3.24, $p=0.002$ ) and cognitive fatigue was associated with the MCS $(\mathrm{t}=4.82, p=0.002)$. Cognitive fatigue was not associated with PCS $(\mathrm{t}=-0.31, p=0.761)$ and physical fatigue was not associated with MCS ( $\mathrm{t}=$ 1.90, $p=0.063$ ) [90].

\section{Multiple sclerosis quality of Life-54}

Four studies used the MSQOL-54 instrument to evaluate QoL $[11,12,17,18]$.

One study examined the relationship between physical, cognitive, and social fatigue measured using FIS with overall QoL, cognitive QoL, and sexual QoL. For each fatigue outcome, the study adjusted for depression, disease severity and the remaining two fatigue types [18]. Physical fatigue was significantly predictive of overall QoL $(\beta=-0.785, p=0.0001)$ but not cognitive or sexual QoL.

Three studies used the FSS to measure fatigue. A large international study reported that for a one-point 
Table 5 Results - Humanistic burden

\begin{tabular}{|c|c|c|c|c|c|c|c|c|}
\hline Author (year) & Type of Analysis & $\begin{array}{l}\text { Sample } \\
\text { Size }\end{array}$ & $\begin{array}{l}\text { Cut-off for } \\
\text { Fatigue }\end{array}$ & Outcome & Predictor(s) & Value & $95 \% \mathrm{Cl}$ & $\begin{array}{l}p- \\
\text { value }\end{array}$ \\
\hline \multirow[t]{2}{*}{ Cioncoloni (2014) } & \multirow[t]{2}{*}{$\begin{array}{l}\text { Binary logistic } \\
\text { regression }\end{array}$} & \multirow[t]{2}{*}{57} & \multirow[t]{2}{*}{$F S S \geq 5$} & PCS (SF-36) $<40$ & \multirow[t]{2}{*}{ FSS $\geq 5$} & $\begin{array}{l}\mathrm{OR}= \\
11.00\end{array}$ & $2.97,40.78$ & $<0.001$ \\
\hline & & & & MCS $($ SF-36) $<40$ & & $\mathrm{OR}=8.64$ & $2.39,31.28$ & 0.001 \\
\hline \multirow[t]{2}{*}{ Filho (2019) ${ }^{\text {a }}$} & \multirow{2}{*}{$\begin{array}{l}\text { Multiple linear } \\
\text { regression }\end{array}$} & \multirow[t]{2}{*}{31} & \multirow[t]{2}{*}{ NR } & Vitality (SF-36) & \multirow[t]{2}{*}{ NR; included FSS (cut-off NR) } & NR & NR & 0.006 \\
\hline & & & & Physical Function (SF-36) & & NR & NR & 0.001 \\
\hline \multirow[t]{9}{*}{ Fricska-Nagy (2016) } & \multirow[t]{9}{*}{$\begin{array}{l}\text { Multiple linear } \\
\text { regression }\end{array}$} & \multirow[t]{9}{*}{428} & \multirow[t]{9}{*}{ NR } & \multirow[t]{3}{*}{ Overall QoL (MSQOL-54) } & $\begin{array}{l}\text { BDI-I, EDSS, cognitive FIS (cut-off NR), } \\
\text { physical FIS, social FIS }\end{array}$ & $\beta=0.094$ & NR & 0.320 \\
\hline & & & & & $\begin{array}{l}\text { BDI-I, EDSS, cognitive FIS, physical FIS } \\
\text { (cut-off NR), social FIS }\end{array}$ & $\begin{array}{l}\beta= \\
-0.785\end{array}$ & NR & 0.0001 \\
\hline & & & & & $\begin{array}{l}\text { BDI-I, EDSS, cognitive FIS, physical FIS, } \\
\text { social FIS (cut-off NR) }\end{array}$ & $\begin{array}{l}\beta=- \\
0.152\end{array}$ & NR & 0.0001 \\
\hline & & & & \multirow[t]{3}{*}{$\begin{array}{l}\text { Cognitive QoL (MSQOL- } \\
\text { 54) }\end{array}$} & $\begin{array}{l}\text { BDI-I, EDSS, cognitive FIS (cut-off NR), } \\
\text { physical FIS, social FIS }\end{array}$ & $\begin{array}{l}\beta=- \\
0.550\end{array}$ & NR & 0.0001 \\
\hline & & & & & $\begin{array}{l}\text { BDI-I, EDSS, cognitive FIS, physical FIS } \\
\text { (cut-off NR), social FIS }\end{array}$ & $\begin{array}{l}\beta= \\
-0.051\end{array}$ & NR & 0.475 \\
\hline & & & & & $\begin{array}{l}\text { BDI-I, EDSS, cognitive FIS, physical FIS, } \\
\text { social FIS (cut-off NR) }\end{array}$ & $\begin{array}{l}\beta= \\
-0.130\end{array}$ & NR & 0.097 \\
\hline & & & & \multirow[t]{3}{*}{ Sexual QoL (MSQOL-54) } & $\begin{array}{l}\text { BDI-I, EDSS, cognitive FIS (cut-off NR), } \\
\text { physical FIS, social FIS }\end{array}$ & $\begin{array}{l}\beta= \\
-0.249\end{array}$ & NR & 0.001 \\
\hline & & & & & $\begin{array}{l}\text { BDI-I, EDSS, cognitive FIS, physical FIS } \\
\text { (cut-off NR), social FIS }\end{array}$ & $\beta=0.008$ & NR & 0.926 \\
\hline & & & & & $\begin{array}{l}\text { BDI-I, EDSS, cognitive FIS, physical FIS, } \\
\text { social FIS (cut-off NR) }\end{array}$ & $\begin{array}{l}\beta= \\
-0.185\end{array}$ & NR & 0.058 \\
\hline \multirow[t]{2}{*}{$\begin{array}{l}\text { Goksel Karatepe } \\
\text { (2011) }\end{array}$} & \multirow[t]{2}{*}{$\begin{array}{l}\text { Hierarchical } \\
\text { regression }\end{array}$} & \multirow[t]{2}{*}{79} & \multirow[t]{2}{*}{$F S S \geq 4$} & $\begin{array}{l}\text { Physical health (MSQOL- } \\
\text { 54) }\end{array}$ & \multirow[t]{2}{*}{$\begin{array}{l}\text { Disease course, education level, } \\
\text { employment status, BDI, EDSS, FSS } \geq \mathbf{4}\end{array}$} & $\begin{array}{l}\beta= \\
-1.641\end{array}$ & $\begin{array}{l}-2.99 \\
-0.29\end{array}$ & 0.018 \\
\hline & & & & Mental health (MSQOL-54) & & $\begin{array}{l}\beta= \\
-1.652\end{array}$ & $\begin{array}{l}-3.26 \\
-0.04\end{array}$ & 0.045 \\
\hline \multirow[t]{4}{*}{ Gullo (2019) } & \multirow[t]{4}{*}{ T-test } & \multirow[t]{4}{*}{62} & \multirow{4}{*}{$\begin{array}{l}\text { MFIS, Cognitive } \\
>20, \text { Physical > } 23\end{array}$} & \multirow[t]{2}{*}{ Physical summary (SF-36) } & Cognitive fatigue (low vs. high; MFIS) & $t=-0.31$ & NA & 0.761 \\
\hline & & & & & Physical fatigue (low vs. high; MFIS) & $t=3.24$ & NA & 0.002 \\
\hline & & & & \multirow[t]{2}{*}{ Mental summary (SF-36) } & Cognitive fatigue (low vs. high; MFIS) & $t=4.82$ & NA & 0.001 \\
\hline & & & & & Physical fatigue (low vs. high; MFIS) & $t=1.90$ & NA & 0.063 \\
\hline $\begin{array}{l}\text { Kaya Aygunoglu } \\
(2015)\end{array}$ & $\begin{array}{l}\text { Pearson's } \\
\text { correlation }\end{array}$ & 120 & FSS $\geq 4$ & $\begin{array}{l}\text { Physical and mental scores } \\
\text { (MSQOL-54) }\end{array}$ & FSS & $r=-0.58$ & NA & $<0.01$ \\
\hline \multirow[t]{2}{*}{ Leonavicius (2016) } & \multirow[t]{2}{*}{$\begin{array}{l}\text { Multiple linear } \\
\text { regression }\end{array}$} & \multirow[t]{2}{*}{137} & $\mathrm{FSS} \geq 4$ & $F S S \geq 4$ & $\begin{array}{l}\text { Gender, age, residence, education, } \\
\text { marital status, professional activity, } \\
\text { duration of RRMS, EDSS, DMT, sleep } \\
\text { problems, HADS-D, HADS-A, MCS } \\
<50 \text { (SF-36), PCS < } \mathbf{5 0} \text { (SF-36) }\end{array}$ & $\mathrm{OR}=3.82$ & $1.44,5.54$ & NR \\
\hline & & & & & $\begin{array}{l}\text { Gender, age, residence, education, } \\
\text { marital status, professional activity, } \\
\text { duration of RRMS, EDSS, DMT, sleep } \\
\text { problems, HADS-D, HADS-A, } \\
\mathbf{M C S}<\mathbf{5 0} \text { (SF-36), PCS < } 50 \text { (SF-36) }\end{array}$ & NR & NR & $>0.05$ \\
\hline Schmidt (2019) & $\begin{array}{l}\text { Multivariate } \\
\text { linear regression }\end{array}$ & 254 & $\begin{array}{l}\text { FSMC } \geq 43 \text { mild, } \\
\geq 53 \text { moderate, }\end{array}$ & Overall QoL (MusiQoL) & $\begin{array}{l}\text { Physical exercise, family status, } \\
\text { occupation, CES-D, FSMC (cut-off NR) }\end{array}$ & $\beta=4.75$ & $1.73,7.78$ & 0.002 \\
\hline & & & $\geq 63$ severe & & $\begin{array}{l}\text { Family status, occupation, EDSS score, } \\
\text { CES-D, FSMC (cut-off NR) }\end{array}$ & $\beta=3.46$ & $0.51,6.41$ & 0.022 \\
\hline & & & & & CES-D, FSMC, EDSS score (cut-off NR) & $\beta=4.98$ & $2.10,7.87$ & 0.001 \\
\hline & & & & & $\begin{array}{l}\text { CES-D, FSMC, occupation, EDSS score } \\
\text { (cut-off NR) }\end{array}$ & $\beta=4.17$ & $1.29,7.05$ & 0.005 \\
\hline Takemoto (2015) & Wilcoxon test & 210 & $\begin{array}{l}\text { MFIS-BR Absent: } \\
\leq 38 \text { points, Low: } \\
39-58 \text { points, High: } \\
\geq 59 \text { points }\end{array}$ & $\begin{array}{l}\text { Utility score (Brazilian } \\
\text { and UK algorithm) }\end{array}$ & MFIS-BR (absent vs. low vs. high) & NR & NA & $<0.001$ \\
\hline
\end{tabular}


Table 5 Results - Humanistic burden (Continued)

\begin{tabular}{|c|c|c|c|c|c|c|c|c|}
\hline Author (year) & Type of Analysis & $\begin{array}{l}\text { Sample } \\
\text { Size }\end{array}$ & $\begin{array}{l}\text { Cut-off for } \\
\text { Fatigue }\end{array}$ & Outcome & Predictor(s) & Value & $95 \% \mathrm{Cl}$ & $\begin{array}{l}p \text { - } \\
\text { value }\end{array}$ \\
\hline Taveira (2019) & T-test & 39 & MFIS $\geq 38$ & FAMS & MFIS (fatigued vs non-fatigued) & NR & NA & 0.001 \\
\hline \multirow[t]{4}{*}{ Weiland (2015) ${ }^{\mathrm{b}}$} & \multirow{4}{*}{$\begin{array}{l}\text { Binary logistic } \\
\text { regression }\end{array}$} & 2090 & \multirow[t]{4}{*}{$F S S \geq 4$} & \multirow[t]{4}{*}{$\mathrm{FSS} \geq 4$} & Overall HRQoL domain (MSQOL-54) & $\mathrm{OR}=0.94$ & $0.93,0.94$ & $<0.001$ \\
\hline & & 1802 & & & $\begin{array}{l}\text { Physical health composite } \\
\text { (MSQOL-54) }\end{array}$ & $\mathrm{OR}=0.91$ & $0.90,0.92$ & $<0.001$ \\
\hline & & 2131 & & & Energy domain (MSQOL-54) & $\mathrm{OR}=0.92$ & $0.92,0.93$ & $<0.001$ \\
\hline & & 2047 & & & $\begin{array}{l}\text { Mental health composite } \\
\text { (MSQOL-54) }\end{array}$ & $\mathrm{OR}=0.94$ & $0.93,0.94$ & $<0.001$ \\
\hline
\end{tabular}

${ }^{\mathrm{a} C o n f e r e n c e ~ a b s t r a c t ~}$

${ }^{b}$ For every increase of one point in overall MSQOL-54 the odds of clinically significant fatigue reduced by $0.06,0.09,0.08,0.06$, respectively

Abbreviations: BDI Beck Depression Inventory, BDI-I Beck Depression Inventory-First Edition, CES-D Center for Epidemiological Studies Depression Scale, CI confidence interval, DMT disease-modifying therapy, EDSS Expanded Disability Status Scale, FAMS Functional Assessment of Multiple Sclerosis quality of life scale, FIS Fatigue Impact Scale, FSMC Fatigue Scale for Motor and Cognitive functions, FSS Fatigue Severity Scale, HADS-A Hospital Anxiety and Depression Scale - Anxiety, HADS-D Hospital Anxiety and Depression Scale - Depression, HROoL health-related quality of life, MCS mental component summary score of SF-36, MFIS Modified Fatigue Impact Scale, MFIS-BR MFIS, Brazilian

Portuguese version, MSQOL-54 Multiple Sclerosis Quality of Life-54, MusiQoL Multiple Sclerosis International Quality of Life questionnaire, NR not reported, OR odds ratio, PCS physical component summary of SF-36, QoL quality of life, RRMS relapsing-remitting multiple sclerosis, SF-36 36-item Short Form health survey

increase in any of the evaluated domains/composites of the MSQOL-54 (i.e., the overall QoL domain, the physical health composite, the energy domain, and the mental health composite), the odds of clinically significant fatigue ( $\mathrm{FSS} \geq 4$ ) were reduced ( $\mathrm{OR}=0.94$ [95\% CI: 0.93, 0.94]; $\mathrm{OR}=0.91$ [95\% CI: 0.90, 0.92]; $\mathrm{OR}=0.92$ [95\% CI: 0.92, 0.93]; OR $=0.94$ [95\% CI: 0.93, 0.94], respectively) [11]. One study from Turkey, adjusting for disease course, education level, employment status, depression, and disease severity, found that fatigue $(F S S \geq 4)$ was predictive of physical and mental health based on the MSQOL-54 ( $\beta=-1.641$ [95\% CI: $-2.99,-0.29] ; \beta=-$ 1.652 [95\% CI: $-3.26,-0.04]$, respectively) [12].

Finally, a second study conducted in Turkey found a strong negative correlation between fatigue $(\mathrm{FSS} \geq 4)$ and the MSQOL-54 physical and mental scores $(\mathrm{r}=-0.58$, $p<0.01)$ [17].

\section{Multiple sclerosis international quality of life}

One German study measured QoL using the MusiQoL instrument and the FSMC (cut-off not reported) to measure fatigue [92]. Four analyses were performed with different predictors, and adjusted for different combinations of physical exercise, family status, occupations, depression and disease severity. All found fatigue to be predictive of overall QoL ( $\beta$ ranged from 3.46 to 4.98 and $p$ values ranged from 0.001 to 0.022$)$ [92].

\section{Functional assessment of multiple sclerosis}

One study conducted in Brazil used the FAMS instrument to measure QoL and the MFIS to evaluate fatigue [94]. FAMS score was significantly lower in patients who reported the presence of fatigue $(p=0.001$, Student's ttest) [94].

\section{Utilities}

One Brazilian study used the EQ-5D-3L to investigate the relationship between fatigue and utilities [93].
Fatigue was measured using the MFIS-BR. MS patients were categorized based on the MFIS-BR score into three groups; absent impact, low impact, and high impact of fatigue. The study reported significant differences between the utility scores between the three fatigue groups $(p<0.001)$, indicating a relationship between fatigue and utilities [93].

\section{Discussion}

A comprehensive SLR was conducted following prespecified inclusion/exclusion criteria in order to understand the burden of MS-related fatigue through a descriptive summary of the published literature, and to identify gaps in current knowledge. Outcomes of interest included prevalence, economic burden, and humanistic burden of MS-related fatigue in patients of any age.

Across studies of adults with sample sizes of $>300$ in which a validated fatigue-specific scale was used, and the population was not limited to CIS or non-disabled patients, the prevalence of fatigue ranged from 36.5 to $78.0 \%$. In contrast, when considering all adult studies irrespective of type of MS, disability status, and tool used to estimate fatigue, prevalence ranged from 18.2 to $97.0 \%$.

Nine studies reported data on the economic burden of fatigue in pwMS with fatigue analyzed as a categorical parameter. Of these, seven reported employment-related outcomes such as employment status and sick leave. Of these, all but one study found statistically significant associations between fatigue and the outcomes of interest. Two studies reported data on direct costs and resource utilization, respectively, and found no associations with fatigue.

In contrast, the evidence obtained from the 20 studies included through the supplemental screening for economic outcomes in which fatigue was assessed as a continuous parameter was more heterogeneous. Similar to the categorical studies, most of these records reported 
data on employment-related outcomes. Of the 11 studies analyzing the impact of fatigue on employment status (e.g. employed vs. unemployed), six found a statistically significant association between the presence of fatigue and unemployment, but no association was found in five other studies. Additionally, eight other studies reported data on the impact of fatigue on outcomes related to work capacity, all of which found a statistically significant association between fatigue and at least one work capacity outcome. One study found an association between fatigue and increased total and drug costs, but no association with indirect costs. Finally, one study found no correlation between fatigue improvement and reduction in sickness benefits.

Over half of the economic studies (including the original and supplementary studies) reported statistically significant associations between fatigue and the economic outcomes evaluated. Of the studies in which the results were not statistically significant, there was a trend for fatigue to be associated with negative impacts on employment-related outcomes.

Eleven studies reported humanistic outcomes, 10 of which were measures of QoL in fatigued and nonfatigued pwMS. A statistically significant association between fatigue and worsening QoL was observed in at least one of the QoL subdomains examined in each of these 10 studies. Only two studies found that physical fatigue was not associated with cognitive or sexual QoL $[18,90]$. In the remaining study, statistically significantly lower utilities were observed in pwMS experiencing fatigue [93].

Numerous DMTs are available for the treatment of MS, however outcomes related to fatigue are not consistently reported in trials and it remains uncertain whether some treatments may be more beneficial for alleviating fatigue than others. Non-specific treatments such as amantadine and modafinil have demonstrated a statistically significant impact on fatigue, although the magnitude of benefit is modest at best, with a recent study showing that these treatments are not superior to placebo [95-99].

An important strength of this review is that it adheres to the PRISMA guidelines to ensure best practices for the conduct and reporting of systematic reviews were followed. In particular, a comprehensive literature search was performed and peer-reviewed by experienced information specialists, a detailed grey literature search was conducted, and study selection was performed according to pre-specified criteria. The limitations of this SLR are largely due to the numerous data gaps in the available literature regarding the burden of MS-related fatigue. Very few studies reported on the direct costs associated with fatigue in pwMS. Data were also somewhat sparse for indirect costs; although employment-related outcomes were available, the findings of these studies were not usually translated into monetary values. Therefore, few studies have quantified the indirect financial losses incurred by pwMS experiencing fatigue, their families, and society. The SLR also identified a paucity of longitudinal studies of the impact of fatigue throughout a patient's life. Moreover, because of the heterogeneity in fatigue scales, methods, and outcome measures between studies, meaningful quantitative synthesis of results across studies was not feasible.

\section{Conclusions}

Clinically relevant fatigue affects a majority of pwMS. There is considerable evidence that the presence of $\mathrm{fa}$ tigue is associated with poorer employment outcomes, however there was sparse and conflicting evidence as to whether fatigue is associated with greater healthcare costs. There was a lack of evidence regarding the burden of fatigue on caregivers of pwMS, or costs to society more broadly, therefore further study in these areas is required. MS-related fatigue appears to have a negative impact on QoL as measured by both generic HRQoL instruments and MS-specific instruments. It is expected that treatments alleviating fatigue may help mitigate the economic and humanistic burden of this prevalent manifestation of MS.

\section{Abbreviations}

AAN: American Neurology Association; ACTRIMS: Americas Committee for Treatment and Research in Multiple Sclerosis; adjRR : Adjusted rate ratio; AESS: Apathy Evaluation Scale; AMCP: Academy of Managed Care Pharmacy; ANA: American Neurology Association; ANOVA: Analysis of variance;

BDI: Beck Depression Inventory; BDI-I: Beck Depression Inventory-First Edition; BDI-II: Beck Depression Inventory-Second Edition; BOI: Burden of illness; CESD: Center for Epidemiological Studies Depression Scale; Cl: Confidence interval; CIS: Clinically isolated syndrome; CPS: Cognition Performance Scale; D-FIS : Daily Fatigue Impact Scale; DMT: Disease-modifying therapy; EAN: European Academy of Neurology; EBMR: Evidence-Based Medicine Reviews; ECTRIMS: European Committee for Treatment and Research in Multiple Sclerosis; EDSS: Expanded Disability Status Scale; EQ-5D: EuroQoL5D; FACIT: Functional Assessment of Chronic Illness Therapy;

FAMS: Functional Assessment of Multiple Sclerosis; FIS: Fatigue Impact Scale; FPS: Fatigue Performance Scale; FSMC : Fatigue Scale for Motor and Cognitive functions; FSS: Fatigue Severity Score; HADS-A: Hospital Anxiety and Depression Scale - Anxiety; HADS-D: Hospital Anxiety and Depression Scale - Depression; HPS: Hand function Performance Scale; HR: Hazard ratio; HRQoL: Health-related quality of life; HUI: Health Utility Index;

ISPOR: International Society for Pharmacoeconomics and Outcomes; KNS: Hope for Success Questionnaire; MCS: Mental component summary score of SF-36; MFIS: Modified Fatigue Impact Scale; MS: Multiple sclerosis; MSQOL-54: Multiple Sclerosis Quality of Life-54; MusiQoL: Multiple Sclerosis International Quality of Life questionnaire; N/A: Not applicable; NFISMS: Neurological Fatigue Index - Multiple Sclerosis; NFIS-MS/BR: Neurological Fatigue Index - Multiple Sclerosis, Brazilian Portuguese version; NHS: National Health Service; NMA: Network meta-analysis; NR: Not reported; OR: Odds ratio; PCS: Physical component summary of SF-36; PDDS: Patient Determined Disease Steps; PICOS: Population, intervention, comparator, outcome, and study design; PPMS: Primary progressive MS; PQD5 : Perceived Deficits Questionnaire 5-items version; PRESS: Peer Review of Electronic Search Strategies; PRISMA: Preferred Reporting Items for Systematic Reviews and Meta-Analyses; pwMS: People with multiple sclerosis; RCT : Randomized controlled trial; RIS : Radiologically isolated syndrome; RRMS : Relapsingremitting multiple sclerosis; SF-36 : 36-item Short Form health survey; SLR 
: Systematic literature review; SPMS : Secondary progressive multiple sclerosis; VAS: Visual analogue scale

\section{Supplementary Information}

The online version contains supplementary material available at https://doi. org/10.1186/s12883-021-02396-1.

Additional file 1: Search strategies. Full epidemiology search strategy and full economic and quality of life search strategy.

Additional file 2: List of studies excluded from the SLR. Full references of excluded studies grouped by reason for exclusion

\section{Additional file 3: Study and baseline characteristics of included} studies. File includes three tables: 1) Study and baseline characteristics Epidemiology; 2) Study and baseline characteristics - Economic burden (fatigue assessed as categorical); and 3) Study and baseline characteristics - Humanistic burden.

Additional file 4: Economic studies reporting fatigue as a linear variable. File includes two tables: 1) Baseline and study characteristics for economic studies reporting fatigue as a linear variable; and 2) Results of economic studies reporting fatigue as a linear variable.

\section{Acknowledgements}

Not applicable.

\section{Authors' contributions}

All authors made substantive intellectual contributions to this study to qualify as authors. All authors participated in study design through drafting or approval of the protocol. AOR, OK, EW, and LC contributed to the literature search. AOR, OK, EW, and LC worked on data collection. AOR, AK, OK, EW, LC, and SS analyzed and interpreted the data. AOR and OK wrote the manuscript draft. EW, AK, LC, and SS provided critical review and revisions. All authors reviewed and approved the final version of the manuscript.

\section{Funding}

Sponsorship for this study was provided by Janssen Research \& Development, LLC. The funders had a role in study design and editorial assistance. The corresponding author had full access to all the data in the study and had final responsibility for the decision to submit for publication.

\section{Availability of data and materials}

The authors declare that the data supporting the findings of this study are available within the article and its supplementary information files. Data are also available from the corresponding author, $\mathrm{AK}$, upon reasonable request.

\section{Declarations}

Ethics approval and consent to participate

Not applicable.

\section{Consent for publication}

Not applicable.

\section{Competing interests}

AOR, OK, EW, LC, and SS have disclosed that they are employees of EVERSANA, which received consulting fees from Janssen Research \& Development, LLC in connection with the development of this manuscript. AK is employed by Janssen Research \& Development, LLC. AK has disclosed that he is also a shareholder of Janssen Research \& Development, LLC.

\section{Author details}

${ }^{1}$ EVERSANA, Burlington, Ontario, Canada. ${ }^{2}$ Health Economics and Market Access, Janssen Research \& Development, LLC, Titusville, NJ, USA.
Received: 20 May 2021 Accepted: 3 September 2021

Published online: 02 December 2021

\section{References}

1. Wallin MT, Culpepper WJ, Nichols E, Bhutta ZA, Gebrehiwot TT, Hay SI, et al. Global, regional, and national burden of multiple sclerosis 1990-2016: a systematic analysis for the Global Burden of Disease Study 2016. Lancet Neurol. 2019;18(3):269-85. https://doi.org/10.1016/S1474-4422(18)30443-5.

2. MS international federation. What is MS? [updated 2019-10-14. Available from: https://www.msif.org/about-ms/what-is-ms/.

3. Milo R, Kahana E. Multiple sclerosis: Geoepidemiology, genetics and the environment. Autoimmun Rev. 2010;9(5):A387-A94. https://doi.org/10.1016/ j.autrev.2009.11.010

4. Chitnis T, Glanz B, Jaffin S, Healy B. Demographics of pediatric-onset multiple sclerosis in an MS center population from the northeastern United States. Mult Scler J. 2009;15(5):627-31. https://doi.org/10.1177/1352458508101933.

5. National Multiple Sclerosis Society. Types of MS [Available from: https:// www.nationalmssociety.org/What-is-MS/Types-of-MS.

6. Multiple Sclerosis Clinical Practice Guidelines. Fatigue and multiple sclerosis: evidence-based management strategies for fatigue in multiple sclerosis. Washington D.C.: Paralyzed Veterans of America; 1998.

7. Freal JE, Kraft GH, Coryell JK. Symptomatic fatique in multiple sclerosis. Arch Phys Med Rehabil. 1984;65(3):135-8.

8. Krupp L. Mechanisms, measurement, and management of fatique in multiple sclerosis. In: Thompson A, Polman C, Hohfeld R, editors. Multiple sclerosis: clinical challenges and controversies. London: Martin Dunitz; 1997.

9. Fisk JD, Pontefract A, Ritvo PG, Archibald CJ, Murray TJ. The impact of fatigue on patients with multiple sclerosis. Can J Neurol Sci. 1994;21(1):9-14. https://doi.org/10.1017/\$0317167100048691.

10. Hadjimichael O, Vollmer T, Oleen-Burkey M. Fatigue characteristics in multiple sclerosis: the north American research committee on multiple sclerosis (NARCOMS) survey. Health Qual Life Outcomes. 2008;6(1):100. https://doi.org/10.1186/1477-7525-6-100.

11. Weiland TJ, Jelinek GA, Marck CH, Hadgkiss EJ, Meer DMvd, Pereira NG, et al Clinically significant fatigue: prevalence and associated factors in an international sample of adults with multiple sclerosis recruited via the internet. PLoS One. 2015;10(2):e0115541, 2015. https://doi.org/10.1371/ journal.pone.0115541.

12. Goksel Karatepe A, Kaya T, Gunaydn R, Demirhan A, Ce P, Gedizlioglu M. Quality of life in patients with multiple sclerosis: the impact of depression, fatigue, and disability. Int J Rehabil Res. 2011;34(4):290-8. https://doi.org/1 0.1097/MRR.0b013e32834ad479.

13. Doesburg D, Vennegoor A, Uitdehaag BMJ, van Oosten BW. High work absence around time of diagnosis of multiple sclerosis is associated with fatigue and relapse rate. Mult Scler Relat Disord. 2019;31:32-7. https://doi. org/10.1016/j.msard.2019.03.011.

14. Moher D, Liberati A, Tetzlaff J, Altman DG, The PG. Preferred reporting items for systematic reviews and Meta-analyses: The PRISMA statement. PLoS Med. 2009;6(7):e1000097. https://doi.org/10.1371/journal.pmed.1000097.

15. McGowan J, Sampson M, Salzwedel DM, Cogo E, Foerster V, Lefebvre C. PRESS peer review of electronic search strategies: 2015 guideline statement. J Clin Epidemiol. 2016;75:40-6. https://doi.org/10.1016/j. jclinepi.2016.01.021.

16. Canadian Agency for Drugs and Technologies in Health. Grey Matters: a practical tool for searching health-related grey literature [updated May 8, 2019.

17. Kaya Aygunoglu S, Celebi A, Vardar N, Gursoy E. Correlation of fatigue with depression, disability level and quality of life in patients with multiple sclerosis. Noro Psikiyatr Ars. 2015;52(3):247-51. https://doi.org/10.5152/npa.2015.8714.

18. Fricska-Nagy Z, Fuvesi J, Rozsa C, Komoly S, Jakab G, Csepany T, et al. The effects of fatigue, depression and the level of disability on the healthrelated quality of life of glatiramer acetate-treated relapsing-remitting patients with multiple sclerosis in Hungary. Mult Scler Relat Disord. 2016;7: 26-32. https://doi.org/10.1016/j.msard.2016.02.006.

19. Razazian N, Shokrian N, Bostani A, Moradian N, Tahmasebi S. Study of fatigue frequency and its association with sociodemographic and clinical variables in patients with multiple sclerosis. Neurosciences (Riyadh). 2014; 19(1):38-42.

20. Alvarenga-Filho H, Papais-Alvarenga RM, Carvalho SR, Clemente HN, Vasconcelos CC, Dias RM. Does fatigue occur in MS patients without disability? Int J Neurosci. 2015;125(2):107-15. https://doi.org/10.3109/00207454.2014.909415. 
21. Anens E, Emtner M, Zetterberg L, Hellstrom K. Physical activity in subjects with multiple sclerosis with focus on gender differences: a survey. BMC Neurol. 2014;14:47.

22. Battaglia M, Kobelt G, Ponzio M, Berg J, Capsa D, Dalen J, et al. New insights into the burden and costs of multiple sclerosis in Europe: Results for Italy. Multiple Sclerosis (Houndmills, Basingstoke, England). 2017;23(2_suppl):104.

23. Calabrese P, Kobelt G, Berg J, Capsa D, Eriksson J. Sclerosis Platform European M. New insights into the burden and costs of multiple sclerosis in Europe: Results for Switzerland. Multiple Sclerosis (Houndmills, Basingstoke, England). 2017;23(2_suppl):192.

24. Flachenecker P, Kobelt G, Berg J, Capsa D, Gannedahl M. Sclerosis Platform European M. New insights into the burden and costs of multiple sclerosis in Europe: Results for Germany. Multiple Sclerosis (Houndmills, Basingstoke, England). 2017;23(2_suppl):78.

25. Hadgkiss EJ, Jelinek GA, Weiland TJ, Pereira NG, Marck CH, van der Meer DM. Methodology of an International Study of People with Multiple Sclerosis Recruited through Web 2.0 Platforms: Demographics, Lifestyle, and Disease Characteristics. Neurol Res Int. 2013;2013:580596.

26. Havrdova E, Kobelt G, Berg J, Capsa D, Gannedahl M, Dolezal T, et al. New insights into the burden and costs of multiple sclerosis in Europe: Results of the Czech Republic. Multiple Sclerosis (Houndmills, Basingstoke, England). 2017;23(2_suppl):41.

27. Kratz AL, Ehde DM, Hanley MA, Jensen MP, Osborne TL, Kraft GH. Crosssectional examination of the associations between symptoms, community integration, and mental health in multiple sclerosis. Arch Phys Med Rehabil. 2016;97(3):386-94. https://doi.org/10.1016/j.apmr.2015.10.093.

28. Labuz-Roszak B, Kubicka-Baczyk K, Pierzchala K, Machowska-Majchrzak A, Skrzypek M. Fatigue and its association with sleep disorders, depressive symptoms and anxiety in patients with multiple sclerosis. NeurolNeurochir Pol. 2012;46(4):309-17. https://doi.org/10.5114/ninp.2012.30261.

29. Lebrun-Frenay C, Kobelt G, Berg J, Capsa D, Gannedahl M. Sclerosis Platform European M. New insights into the burden and costs of multiple sclerosis in Europe: Results for France. Multiple Sclerosis (Houndmills, Basingstoke, England). 2017;23(2_suppl):65.

30. Oreja-Guevara C, Kobelt G, Berg J, Capsa D, Eriksson J. Sclerosis Platform European M. New insights into the burden and costs of multiple sclerosis in Europe: Results for Spain. Multiple Sclerosis (Houndmills, Basingstoke, England). 2017;23(2_suppl):166.

31. Parrish JB, Weinstock-Guttman B, Smerbeck A, Benedict RH, Yeh EA. Fatigue and depression in children with demyelinating disorders. J Child Neurol. 2013;28(6):713-8. https://doi.org/10.1177/0883073812450750.

32. Pentek M, Kobelt G, Berg J, Capsa D, Dalen J, Biro Z, et al. New insights into the burden and costs of multiple sclerosis in Europe: Results for Hungary. Multiple Sclerosis (Houndmills, Basingstoke, England). 2017;23(2_suppl):91.

33. Pokryszko-Dragan A, Dziadkowiak E, Zagrajek M, Slotwinski K, Gruszka E, Bilinska $M$, et al. Cognitive performance, fatigue and event-related potentials in patients with clinically isolated syndrome. Clin Neurol Neurosurg. 2016; 149:68-74. https://doi.org/10.1016/j.clineuro.2016.07.022.

34. Reilly GD, Mahkawnghta AS, Jelinek PL, Livera AMD, Weiland TJ, Brown CR, et al. International Differences in Multiple Sclerosis Health Outcomes and Associated Factors in a Cross-sectional Survey. Front Neurol. 2017:8:229.

35. Rooney S, Wood L, Moffat F, Paul L. Prevalence of fatigue and its association with clinical features in progressive and non-progressive forms of multiple sclerosis. Multiple Sclerosis Related Disord. 2019;28:276-82. https://doi.org/1 0.1016/j.msard.2019.01.011.

36. Runia TF, Jafari N, Siepman DA, Hintzen RQ. Fatigue at time of CIS is an independent predictor of a subsequent diagnosis of multiple sclerosis. J Neurol Neurosurg Psychiatry. 2015;86(5):543-6. https://doi.org/10.1136/jnnp-2014-308374.

37. Selmaj K, Kobelt G, Berg J, Orlewska E, Capsa D, Dalen J, et al. New insights into the burden and costs of multiple sclerosis in Europe: Results for Poland. Multiple Sclerosis (Houndmills, Basingstoke, England). 2017;23(2_suppl):130.

38. Thompson A, Kobelt G, Berg J, Capsa D, Eriksson J, Miller D, et al. New insights into the burden and costs of multiple sclerosis in Europe: Results for the United Kingdom. Multiple Sclerosis (Houndmills, Basingstoke, England). 2017;23(2_suppl):204

39. Uitdehaag B, Kobelt G, Berg J, Capsa D, Dalen J. Sclerosis Platform European M. New insights into the burden and costs of multiple sclerosis in Europe: Results for the Netherlands. Multiple Sclerosis (Houndmills, Basingstoke, England). 2017;23(2_suppl):117.
40. Weiland TJ, Livera AMD, Brown CR, Jelinek GA, Aitken Z, Simpson SL, et al. Health outcomes and lifestyle in a sample of people with multiple sclerosis (HOLISM): longitudinal and validation cohorts. Front Neurol. 2019;9:1074. https://doi.org/10.3389/fneur.2018.01074.

41. Wunderlich M, Heesen C, Haase R, Stellmann JP, Angstwurm K, Marziniak M, et al. Early stages of disability in patients with multiple sclerosis by physician and patient-reported outcomes: A two-year study. Mult Scler J. 2018; Conference(2 Supplement):923.

42. Fiest KM, Fisk JD, Patten SB, Tremlett H, Wolfson C, Warren S, et al. Fatigue and comorbidities in multiple sclerosis. Int J MS Care. 2016;18(2):96-104. https://doi.org/10.7224/1537-2073.2015-070.

43. Goretti B, Ghezzi A, Portaccio E, Lori S, Zipoli V, Razzolini L, et al. Psychosocial issue in children and adolescents with multiple sclerosis. Neurol Sci. 2010;31(4):467-70. https://doi.org/10.1007/s10072-010-0281-x.

44. KSVs G, Blaschek A, Calabrese P, Rostasy K, Huppke P, Kessler JJ, et al. Fatigue and depression predict health-related quality of life in patients with pediatriconset multiple sclerosis. Multiple Sclerosis Related Disord. 2019;36:101368.

45. Florea A, Maurey H, Sauter ML, Bellesme C, Sevin C, Deiva K. Fatigue, depression, and quality of life in children with multiple sclerosis: a comparative study with other demyelinating diseases. DevMed Child Neurol. 2019;2019.

46. Garcia L, Alvarenga R, Bento C, Filho HA. Evaluation of persistent fatigue in multiple sclerosis patient with low disability. Neurol Therapy. 2019; Conference(Supplement 1):S2.

47. Larnaout F, Mrabet S, Nasri A, Hmissi L, Djabara MB, Gargouri A, et al. Interplay Between Fatigue and Sleep Disturbances in Patients with Multiple Sclerosis. Multiple Sclerosis Related Disord. 2018;Conference:252.

48. Rupprecht S, Kluckow S, Witte O, Schwab M. Sleep disturbances, fatigue, anxiety and depression in multiple sclerosis (MS): results of the German SLEEP-MS Survey. J Sleep Res. 2018; Conference(Supplement 1):188

49. van der Vuurst de Vries RM, JJvd D, Mescheriakova JY, Runia TF, Jafari N, Siepman TA, et al. Fatigue after a first attack of suspected multiple sclerosis. Multiple Sclerosis (Houndmills, Basingstoke, England). 2018;24(7):974.

50. von Bismarck O, Dankowski T, Ambrosius B, Hessler N, Antony G, Ziegler A, et al. Treatment choices and neuropsychological symptoms of a large cohort of early MS. Neurol Neuroimmunol Neuroinflamm. 2018;5(3):e446. https://doi.org/10.1212/NXI.0000000000000446.

51. Wood B, IAvd M, Ponsonby AL, Pittas F, Quinn S, Dwyer T, et al. Prevalence and concurrence of anxiety, depression and fatigue over time in multiple sclerosis. Multiple Sclerosis (Houndmills, Basingstoke, England). 2013;19(2):217.

52. Gravesande K, Storm van's PCA, Blaschek KR, LR PH, JK VM, VK EK, et al. The Multiple Sclerosis Inventory of Cognition for Adolescents (MUSICADO): A brief screening instrument to assess cognitive dysfunction, fatigue and loss of health-related quality of life in pediatric-onset multiple sclerosis. Eur J Paediatr Neurol. 2019;23(6):792.

53. Krupp LB, LaRocca NG, Muir-Nash J, Steinberg AD. The fatigue severity scale: application to patients with multiple sclerosis and systemic lupus erythematosus. Arch Neurol. 1989;46(10):1121-3. https://doi.org/10.1001/a rchneur.1989.00520460115022.

54. Lerdal A, Wahl AK, Rustoen T, Hanestad BR, Moum T. Fatigue in the general population: a translation and test of the psychometric properties of the Norwegian version of the fatigue severity scale. Scand J Public Health. 2005; 33(2):123-30. https://doi.org/10.1080/14034940410028406.

55. Flachenecker $P$, Kümpfel T, Kallmann B, Gottschalk M, Grauer O, Rieckmann $P$, et al. Fatigue in multiple sclerosis: a comparison of different rating scales and correlation to clinical parameters. Mult Scler. 2002;8(6):523-6. https:// doi.org/10.1191/1352458502ms839oa.

56. Veauthier C, Radbruch H, Gaede G, Pfueller CF, Dörr J, Bellmann-Strobl J, et al. Fatigue in multiple sclerosis is closely related to sleep disorders: a polysomnographic cross-sectional study. Mult Scler J. 2011;17(5):613-22. https://doi.org/10.1177/1352458510393772.

57. Fisk JD, Doble SE. Construction and validation of a fatigue impact scale for daily administration (D-FIS). Qual Life Res. 2002;11(3):263-72. https://doi. org/10.1023/A:1015295106602.

58. Penner IK, Raselli C, Stöcklin M, Opwis K, Kappos L, Calabrese P. The fatigue scale for motor and cognitive functions (FSMC): validation of a new instrument to assess multiple sclerosis-related fatigue. Mult Scler. 2009; 15(12):1509-17. https://doi.org/10.1177/1352458509348519. 
59. Fiest KM, Fisk JD, Patten SB, Tremlett H, Wolfson C, Warren S, et al. Fatigue and Comorbidities in Multiple Sclerosis. 2016;18(2):96-104. https://doi.org/1 0.7224/1537-2073.2015-070.

60. da Silva NL, Takemoto MLS, Damasceno A, Fragoso YD, Finkelsztejn A, Becker J, et al. Cost analysis of multiple sclerosis in Brazil: a cross-sectional multicenter study. BMC Health Serv Res. 2016;16(1):102. https://doi.org/10.11 86/s12913-016-1352-3.

61. Grytten N, Skar AB, Aarseth JH, Assmus J, Farbu E, Lode K, et al. The influence of coping styles on long-term employment in multiple sclerosis: a prospective study. Mult Scler. 2017;23(7):1008-17. https:/doi.org/10.1177/1352458516667240.

62. Koziarska D, Krol J, Nocon D, Kubaszewski P, Rzepa T, Nowacki P. Prevalence and factors leading to unemployment in MS (multiple sclerosis) patients undergoing immunomodulatory treatment in Poland. PLoS One. 2018;13(4): e0194117. https://doi.org/10.1371/journal.pone.0194117.

63. Lorefice L, Fenu G, Frau J, Coghe G, Marrosu MG, Cocco E. The impact of visible and invisible symptoms on employment status, work and social functioning in multiple sclerosis. Work. 2018;60(2):263-70. https://doi.org/1 0.3233/WOR-182682.

64. McKay KA, Marrie RA, Fisk JD, Patten SB, Tremlett H. Comorbidities are associated with altered health services use in multiple sclerosis: a prospective cohort study. Neuroepidemiology. 2018;51(1-2):1-10. https://doi.org/10.1159/ 000488799.

65. Salter A, Thomas N, Tyry T, Cutter G, Marrie RA. Employment and absenteeism in working-age persons with multiple sclerosis. J Med Econ. 2017;20(5):493-502. https://doi.org/10.1080/13696998.2016.1277229.

66. Beier M, Hartoonian N, D'Orio VL, Terrill AL, Bhattarai J, Paisner ND, et al. Relationship of perceived stress and employment status in individuals with multiple sclerosis. Work. 2019;62(2):243-9. https://doi. org/10.3233/WOR-192859.

67. Bøe Lunde HM, Telstad W, Grytten N, Kyte L, Aarseth J, Myhr K-M, et al. Employment among patients with multiple sclerosis-a population study. PLoS One. 2014;9(7):e103317-e.

68. Cadden M, Arnett P. Factors associated with employment status in individuals with multiple sclerosis. Int J MS Care. 2015;17(6):284-91. https:// doi.org/10.7224/1537-2073.2014-057.

69. Carnero Contentti E, Lopez P, Balbuena ME, Tkachuk V. Impact of multiple sclerosis on employment and its association with anxiety, Depression, Fatigue and Sleep Disorders; 2018.

70. Doesburg D, Mokkink W, Vennegoor A, Uitdehaag B, van Oosten B. Sick leave in early MS is associated with fatigue and relapse rate, not disability; 2018.

71. Flensner G, Landtblom AM, Soderhamn O, Ek AC. Work capacity and healthrelated quality of life among individuals with multiple sclerosis reduced by fatigue: a cross-sectional study. BMC Public Health. 2013;13(1):224. https:// doi.org/10.1186/1471-2458-13-224.

72. Glanz BI, Degano IR, Rintell DJ, Chitnis T, Weiner HL, Healy BC. Work productivity in relapsing multiple sclerosis: associations with disability, depression, fatigue, anxiety, cognition, and health-related quality of life. Value Health. 2012;15(8):1029-35. https://doi.org/10.1016/j.jval.2012.07.010.

73. Jongen PJ, Wesnes K, van Geel B, Pop P, Sanders E, Schrijver H, et al. Relationship between working hours and power of attention, memory, fatigue, depression and self-efficacy one year after diagnosis of clinically isolated syndrome and relapsing remitting multiple sclerosis. PLoS One. 2014;9(5):e96444. https://doi.org/10.1371/journal.pone.0096444.

74. Moore $\mathrm{P}$, Harding KE, Clarkson H, Pickersgill TP, Wardle M, Robertson NP. Demographic and clinical factors associated with changes in employment in multiple sclerosis. Mult Scler. 2013;19(12):1647-54. https://doi.org/10.11 77/1352458513481396.

75. Ness N-H, Haase R, Cornelissen C, Ziemssen T. Link between health-related quality of life, occupational disability and sick leaves in patients with multiple sclerosis in Germany; 2018

76. Povolo CA, Blair M, Mehta S, Rosehart H, Morrow SA. Predictors of vocational status among persons with multiple sclerosis. Mult Scler Relat Disord. 2019;36:101411. https://doi.org/10.1016/j.msard.2019.101411.

77. Reese JP, John A, Wienemann G, Wellek A, Sommer N, Tackenberg B, et al. Economic burden in a German cohort of patients with multiple sclerosis. Eur Neurol. 2011;66(6):311-21. https://doi.org/10.1159/000331043.

78. Strober LB, Chiaravalloti N, DeLuca J. Should I stay or should I go? A prospective investigation examining individual factors impacting employment status among individuals with multiple sclerosis (MS). Work. 2018;59(1):39-47. https://doi.org/10.3233/WOR-172667.
79. Van der Hiele K, Middelkoop HA, Ruimschotel R, Kamminga NG, Visser LH. A pilot study on factors involved with work participation in the early stages of multiple sclerosis. PLoS One. 2014;9(8):e105673. https://doi.org/10.1371/ journal.pone.0105673.

80. van der Hiele K, van Gorp DAM, Jongen PJ, Reneman MF, van der Klink JJL, Arnoldus EPJ, et al. Disease modifying drug treatment and work functioning in patients with multiple sclerosis. 2018

81. van Gorp DAM, van der Klink J LL, Abma Fl, Jongen PJ, van Lieshout I, Arnoldus EPJ, et al. The capability set for work - correlates of sustainable employability in workers with multiple sclerosis. Health Qual Life Outcomes. 2018;16(1):113. https://doi.org/10.1186/s12955-018-0942-7.

82. Forslin M, Fink K, Hammar U, von Koch L, Johansson S. Predictors for employment status in people with multiple sclerosis: a 10-year longitudinal observational study. Arch Phys Med Rehabil. 2018;99(8):1483-90. https://doi. org/10.1016/j.apmr.2017.12.028.

83. van Gorp DAM, van der Hiele K, Heerings MAP, Jongen PJ, van der Klink JJL, Reneman MF, et al. Cognitive functioning as a predictor of employment status in relapsing-remitting multiple sclerosis: a 2-year longitudinal study. Neurol Sci. 2019;40(12):2555-64. https://doi.org/10.1007/s10072-019-03999-w.

84. Wickstrom A, Dahle C, Vrethem M, Svenningsson A. Reduced sick leave in multiple sclerosis after one year of natalizumab treatment. A prospective ad hoc analysis of the TYNERGY trial. Mult Scler. 2014;20(8):1095-101. https:// doi.org/10.1177/1352458513517590.

85. Chen J, Taylor B, Palmer AJ, Kirk-Brown A, Pv D, Simpson S, et al. Estimating MS-related work productivity loss and factors associated with work productivity loss in a representative Australian sample of people with multiple sclerosis. Mult Scler J. 2019;25(7):994.

86. Strober LB. Quality of life and psychological well-being in the early stages of multiple sclerosis (MS): importance of adopting a biopsychosocial model. Disabil Health J. 2018;11(4):555-61. https://doi. org/10.1016/j.dhjo.2018.05.003

87. Chen J, Taylor B, Palmer AJ, Kirk-Brown A, van Dijk P, Simpson S Jr, et al. Estimating MS-related work productivity loss and factors associated with work productivity loss in a representative Australian sample of people with multiple sclerosis. Mult Scler. 2019;25(7):994-1004. https://doi.org/10.1177/13 52458518781971.

88. Cioncoloni D, Innocenti I, Bartalini S, Santarnecchi E, Rossi S, Rossi A, et al. Individual factors enhance poor health-related quality of life outcome in multiple sclerosis patients. Significance of predictive determinants. J Neurol Sci. 2014;345(1-2):213-9. https://doi.org/10.1016/j. ins.2014.07.050

89. Filho HA, Santos M, Bento C, Bergmann A. Quality of life in patients with multiple sclerosis: A study with patients and caregivers. In: Healthrelated quality of life in patients with multiple sclerosis without disability; 2019.

90. Gullo HL, Fleming J, Bennett S, Shum DHK. Cognitive and physical fatigue are associated with distinct problems in daily functioning, role fulfilment, and quality of life in multiple sclerosis. Mult Scler Relat Disord. 2019;31:11823. https://doi.org/10.1016/j.msard.2019.03.024

91. Leonavicius R. Among multiple sclerosis and fatigue. Neurol Psychiatry Brain Res. 2016;22(3):141-5. https://doi.org/10.1016/j.npbr.2016.08.002.

92. Schmidt $\mathrm{S}$, Jostingmeyer $\mathrm{P}$. Depression, fatigue and disability are independently associated with quality of life in patients with multiple sclerosis: results of a cross-sectional study. Mult Scler Relat Disord. 2019;35: 262-9. https://doi.org/10.1016/j.msard.2019.07.029.

93. Takemoto ML, Lopes da Silva N, Ribeiro-Pereira AC, Schilithz AO, Suzuki C. Differences in utility scores obtained through Brazilian and UK value sets: a cross-sectional study. Health Qual Life Outcomes. 2015;13(1):119. https://doi. org/10.1186/s12955-015-0318-1

94. Taveira FM, Braz NFT, Comini-Frota ER, Teixeira AL, Domingues RB. Disability as a determinant of fatigue in MS patients. Arq Neuropsiquiatr. 2019;77(4): 248-53. https://doi.org/10.1590/0004-282×20190035.

95. Lee D, Newell R, Ziegler L, Topping A. Treatment of fatigue in multiple sclerosis: a systematic review of the literature. Int J Nurs Pract. 2008;14(2): 81-93. https://doi.org/10.1111/j.1440-172X.2008.00670.x.

96. Yang $T$, Wang $L$, Deng XY, Yu G. Pharmacological treatments for fatigue in patients with multiple sclerosis: a systematic review and meta-analysis. J Neurol Sci. 2017;380:256-61. https://doi.org/10.1016/j.jns.2017.07.042.

97. Miller P, Soundy A. The pharmacological and non-pharmacological interventions for the management of fatigue related multiple sclerosis. J Neurol Sci. 2017;381:41-54. https://doi.org/10.1016/j.jns.2017.08.012. 
98. Brañas $P$, Jordan R, Fry-Smith A, Burls A, Hyde C. Treatments for fatigue in multiple sclerosis: a rapid and systematic review. Health Technol Assess. 2000;4(27):1-61. https://doi.org/10.3310/hta4270.

99. Nourbakhsh B, Revirajan N, Morris B, Cordano C, Creasman J, Manquinao M, et al. Safety and efficacy of amantadine, modafinil, and methylphenidate for fatique in multiple sclerosis: a randomised, placebo-controlled, crossover, double-blind trial. Lancet Neurol. 2021;20(1):38-48. https://doi.org/10.1016/ S1474-4422(20)30354-9.

\section{Publisher's Note}

Springer Nature remains neutral with regard to jurisdictional claims in published maps and institutional affiliations.

- fast, convenient online submission

- thorough peer review by experienced researchers in your field

- rapid publication on acceptance

- support for research data, including large and complex data types

- gold Open Access which fosters wider collaboration and increased citations

- maximum visibility for your research: over $100 \mathrm{M}$ website views per year

At $\mathrm{BMC}$, research is always in progress. 